\title{
ARTICLE STIM1 thermosensitivity defines the optimal preference temperature for warm sensation in mice
}

\author{
Xiaoling Liu ${ }^{1}$, Haiping Wang ${ }^{1}$, Yan Jiang ${ }^{1}$, Qin Zheng $^{2}$, Matt Petrus ${ }^{3}$, Mingmin Zhang ${ }^{1}$, Sisi Zheng ${ }^{4}$, Christian Schmedt ${ }^{3}$, \\ Xinzhong Dong ${ }^{2}$ and Bailong Xiao ${ }^{1}$
}

\begin{abstract}
Mammals possess a remarkable ability to sense subtle temperature deviations from the thermoneutral skin temperature of $\sim 33^{\circ} \mathrm{C}$ which ensures precise warm sensation. However, the underlying mechanisms remain unclear. Here we show that STIM1, an endoplasmic reticulum (ER) resident transmembrane protein that responds to both $\mathrm{ER} \mathrm{Ca}^{2+}$ depletion and heat, mediates temperature-induced $\mathrm{Ca}^{2+}$ influx in skin keratinocytes via coupling to Orai $\mathrm{Ca}^{2+}$ channels in plasma membrane. Behaviorally, the keratinocyte-specific knockout of STIM1 shifts the optimal preference temperature (OPT) of mice from $\sim 32{ }^{\circ} \mathrm{C}$ to $\sim 34^{\circ} \mathrm{C}$, resulting in a strikingly reversed preference between $32{ }^{\circ} \mathrm{C}$ and $34^{\circ} \mathrm{C}$. Importantly, the thermally inactive STIM1- $\Delta \mathrm{K}$ knock-in mice show altered OPT and warm preference behaviors as well, demonstrating the requirement of STIM1 thermosensitivity for warm sensation. Furthermore, the wild-type and mutant mice prefer temperatures closer to their respective OPTs, but poorly distinguish temperatures that are equally but oppositely deviated from their OPTs. Mechanistically, keratinocyte STIM1 affects the in vivo warm responses of sensory neurons by likely involving TRPA1 as a downstream transduction channel. Collectively, our data suggest that STIM1 serves as a novel in vivo thermosensor in keratinocytes to define the OPT, which might be utilized as a peripheral reference temperature for precise warm sensation.
\end{abstract}

Cell Research (2019) 29:95-109; https://doi.org/10.1038/s41422-018-0129-0

\section{INTRODUCTION}

Environmental temperature variations can be extreme, ranging from comfortable warm $\left(30^{\circ} \mathrm{C}-42^{\circ} \mathrm{C}\right)$ and cool $\left(15^{\circ} \mathrm{C}-30^{\circ} \mathrm{C}\right)$ to painful heat $\left(>43^{\circ} \mathrm{C}\right)$ and cold $\left(<15^{\circ} \mathrm{C}\right)$. Many species, including mammals, have evolved robust mechanisms to sense such temperature variations to avoid noxious temperatures and seek optimal thermal conditions. ${ }^{1-3}$ For instance, humans not only readily perceive painful heat and cold, but they can also accurately detect as subtle as $1{ }^{\circ} \mathrm{C}$ temperature deviations from our thermoneutral skin temperature of $\sim 33^{\circ} \mathrm{C}$. Thus, it is pivotal to fully understand how mammals sense the full spectrum of temperature variations.

Mammals have specialized thermosensitive sensory neurons located in the trigeminal ganglia (TG) and dorsal root ganglia (DRG), which extend their peripheral nerves into the skin and express thermosensors. ${ }^{1}$ When skin experiences drastic temperature changes, the altered skin temperature is thought to directly activate thermosensors located in the skin-innervating nerve endings of DRG neurons. Following the landmark discovery of the first temperatureactivated channel, the TRPV 1 channel $\left(>43^{\circ} \mathrm{C}\right),{ }^{4}$ a series of thermally activated TRP channels have been identified and proposed to function as thermosensors in DRG neurons. These include the heatactivated TRPV $2\left(>52^{\circ} \mathrm{C}\right),{ }^{5}$ TRPM $3\left(>40^{\circ} \mathrm{C}\right),{ }^{6} \operatorname{TRPM} 2\left(>42^{\circ} \mathrm{C}\right.$ in the presence of $\left.\mathrm{H}_{2} \mathrm{O}_{2}\right)^{7}$ and the cold-activated TRPM $8\left(<25^{\circ} \mathrm{C}-28^{\circ} \mathrm{C}\right)^{8,9}$ and TRPA $1\left(<17^{\circ} \mathrm{C}\right) .{ }^{10}$

Remarkably, ablation of TRPV1- or TRPM8-expressing sensory neurons almost completely abolishes heat or cold sensation, respectively, demonstrating that TRPV1 and TRPM8 serve as molecular markers of heat- and cold-responding neurons. ${ }^{11}$ At the molecular level, mouse knockout studies have unanimously established that TRPM8 plays a critical role in sensing cool temperatures in the range of $10{ }^{\circ} \mathrm{C}-25^{\circ} \mathrm{C} .{ }^{12-14}$ However, individual deletion of the identified heat-activated ion channels cause either modest (e.g., TRPV $1^{15}$ or TRPM $3^{6}$ ) or no defect (e.g., TRPV $2^{16}$ ) in sensing noxious heat, indicating functional redundancy. Indeed, a combinational deletion of TRPV1, TRPM3 and TRPA1 in mice almost completely abolished the cellular and behavioral responses to noxious heat $\left(>45^{\circ} \mathrm{C}\right)$, demonstrating that these thermoTRPs collectively determine noxious heat sensation. ${ }^{17}$ The involvement of cold-activated TRPA1 in noxious heat sensation raises the possibility that these temperature-activated ion channels might indirectly contribute to thermosensation. Indeed, thermoTRPs function as polymodal receptors capable of sensing both temperature and chemical stimuli. Thus, it remains experimentally unaddressed whether the thermosensory process is indeed mediated by the thermosensitivity of thermoTRPs.

\footnotetext{
${ }^{1}$ State Key Laboratory of Membrane Biology; Tsinghua-Peking Joint Center for Life Sciences; IDG/McGovern Institute for Brain Research; School of Pharmaceutical Sciences, Tsinghua University, 100084 Beijing, China; ${ }^{2}$ Departments of Neuroscience, Neurosurgery, and Dermatology, Center of Sensory Biology, Howard Hughes Medical Institute, the Johns Hopkins University School of Medicine, Baltimore, MD 21205, USA; ${ }^{3}$ Genomics Institute of the Novartis Research Foundation, San Diego, CA 92121, USA and ${ }^{4}$ Beijing Key Laboratory of Gene Resource and Molecular Development, College of Life Sciences, Beijing Normal University, 100875 Beijing, China

Correspondence: Bailong Xiao (xbailong@mail.tsinghua.edu.cn)

These authors contributed equally: Xiaoling Liu, Haiping Wang, Yan Jiang, Qin Zheng
}

Received: 4 July 2018 Accepted: 21 November 2018

Published online: 3 January 2019 
Compared to heat and cool sensation, warm sensation is more intriguing and less understood at both the cellular and molecular levels. Given that the thermosensitive DRG nerve endings are imbedded inside the skin, which might have a temperature close to the normal body temperature of $37^{\circ} \mathrm{C}$, it appears paradoxical that subtle temperature deviations (e.g., $32^{\circ} \mathrm{C}-34^{\circ} \mathrm{C}$ ) at the skin surface can effectively alter the local temperature directly experienced by the nerve endings, leading to activation of the residing thermoTRPs with thermoactivation thresholds above $37^{\circ} \mathrm{C}$. Given this reasoning, it has been postulated that skin keratinocytes themselves may sense subtle temperature changes occurring at the skin surface, then indirectly activate downstream sensory neurons for generating warm sensation. ${ }^{18}$ Interestingly, the warm-activated TRPV4 $\left(>28^{\circ} \mathrm{C}\right)$ and TRPV3 $\left(>33^{\circ} \mathrm{C}\right)$ are expressed in skin keratinocytes rather than in DRG neurons. ${ }^{19-21}$ However, mice lacking TRPV3, TRPV4 or both in the C57BL/6 genetic background have an overall minor defect in sensing warm temperatures. $22-26$ Unexpectedly, a recent study has shown that mice lacking the noxious heat-activated TRPV1 have decreased in vivo warm-responding neurons within the range of $35^{\circ} \mathrm{C}-42^{\circ} \mathrm{C}$ and behavioral defects in avoiding a stimulation of $40^{\circ} \mathrm{C} .{ }^{27}$ Another study has shown that mice lacking TRPM2 have defects in distinguishing between $33^{\circ} \mathrm{C}$ and $38^{\circ} \mathrm{C}$. However, TRPM2 expressed in neurons appeared to be activated by a temperature stimulus of $42{ }^{\circ} \mathrm{C}$ only in the presence of $\mathrm{H}_{2} \mathrm{O}_{2},{ }^{7}$ and a recent study has even questioned whether TRPM2 indeed mediates temperature responses in DRG neurons. ${ }^{17}$ These studies raise the possibility that the DRG-expressing TRPV1 and TRPM2 might function as downstream transduction channels instead of direct warm sensors for sensing subtle temperature variations from normal skin temperature. Thus, whether keratinocytes originally contribute to warm sensation and whether there are yet unidentified warm sensors remain unresolved.

We have previously identified STIM1/Orai1 as a novel class of temperature-activated ion channels. ${ }^{28}$ STIM1 and Orai1 constitute the $\mathrm{Ca}^{2+}$ release-activated $\mathrm{Ca}^{2+}$ (CRAC) channel that mediates an important $\mathrm{Ca}^{2+}$ signaling process known as store operated $\mathrm{Ca}^{2+}$ entry (SOCE). ${ }^{29,30}$ SOCE is triggered upon endoplasmic reticulum (ER) $\mathrm{Ca}^{2+}$ store depletion and critical for various signal pathways in many cell types including keratinocytes. ${ }^{31-34}$ STIM1 is the ER Ca ${ }^{2+}$ sensor, ${ }^{35,36}$ while Orai1 is the coupled plasma membrane poreforming subunit to allow $\mathrm{Ca}^{2+}$ influx. ${ }^{37-39}$ In addition to activation by depletion of ER $\mathrm{Ca}^{2+}$ stores, STIM1 is also activated by heating independent of store depletion, with comparable heat sensitivity to some thermoTRPs such as TRPV3. ${ }^{28}$ Interestingly, heat-induced STIM1 activation can lead to Orai1-mediated $\mathrm{Ca}^{2+}$ influx during the cooling phase as a heat off-response. ${ }^{28}$ Previous structurefunction analysis has further revealed that the C-terminal polylysine domain (K-domain) is required for heat-induced STIM1 activation and Orai1-mediated heat off-response, but largely dispensable for store depletion-induced STIM1/Orai1 activation. ${ }^{28}$

Here we have investigated the physiological significance of STIM1 thermosensitivity in somatosensation of temperatures. Our results suggest that keratinocyte-derived STIM1 mediates temperature-induced responses in keratinocytes, which affects the in vivo responsiveness of DRG neurons to warm temperatures by likely involving the DRG-expressing TRPA1 as a downstream transduction channel. Remarkably, keratinocyte-specific knockout of STIM1 shifts the optimal preference temperature (OPT) of mice in the $\mathrm{C} 56 \mathrm{BL} / 6$ genetic background from $\sim 32^{\circ} \mathrm{C}$ to $\sim 34^{\circ} \mathrm{C}$, resulting in a reversed preference between $32^{\circ} \mathrm{C}$ and $34^{\circ} \mathrm{C}$. Importantly, we generated thermally inactive STIM1 knock-in mice by deleting the C-terminal K-domain (STIM1- $\Delta \mathrm{K}$ knock-in mice), which have altered OPT and warm preference behaviors as well, demonstrating the requirement of STIM1 thermosensitivity for warm sensation. Taking advantage of the distinct OPTs possessed by wild-type (WT) and STIM1 mutant mice, we have further examined the mechanism by which mice are capable of detecting subtle temperature variations from the thermoneutral skin temperature of $33^{\circ} \mathrm{C}$. Collectively, by revealing that STIM1 functions as an in vivo warm sensor in keratinocytes, our studies have provided evidence supporting a role for keratinocytes in warm sensation and led us to propose that mammals might utilize the OPT as a reference temperature for detecting subtle skin temperature changes, which enables precise warm sensation.

\section{RESULTS}

Primary keratinocytes show STIM1-dependent temperature responses

To investigate whether the thermosensitivity of STIM1 can contribute to thermosensation, we first examined the expression of STIM1 in primary sensory neurons and keratinocytes. Western blotting revealed relatively low expression of STIM1 in DRG or TG neurons (Fig. 1a). In contrast, more abundant STIM1 protein expression was detected in keratinocytes (Fig. 1a). We therefore focused on investigating STIM1-dependent temperature responses in primary keratinocytes derived from newborn or adult mice by following the previously described culture protocols. $^{26,40}$ The cultured cells showed typical morphology of keratinocytes (Supplementary information, Fig. S1a) and positive staining of the keratinocyte marker, keratin-5 (Supplementary information, Fig. S1b), demonstrating the purity of the cultured primary keratinocytes. We first tested the heat responses of keratinocytes derived from C57BL/6 newborn mice using the Fluorescence Imaging Plate Reader (FLIPR) to measure real-time fluorescent changes of the $\mathrm{Ca}^{2+}$-sensitive Fluo-3 from a cell population. Heating the cells to the upper limit of the body temperature of $42^{\circ} \mathrm{C}$ caused an increase in Fluo-3 signal (heat on), and subsequent cooling back to $25^{\circ} \mathrm{C}$ led to a further increase of the signal (heat off) (Fig. 1b, left panel). Importantly, the increases in Fluo-3 signal during both heat on and off were abolished in the absence of extracellular $\mathrm{Ca}^{2+}$ (Fig. $1 \mathrm{~b}$, left panel), indicating that the heat responses were due to $\mathrm{Ca}^{2+}$ influx rather than release from stores. Heating cells to a noxious temperature of $50^{\circ} \mathrm{C}$ resulted in similar heat responses but with increased amplitudes (Fig. 1b, c). Similar temperature responses were also observed in $\mathrm{HaCaT}$ cells, a human keratinocyte-derived cell line (Supplementary information, Fig. S1c). The heat off-response was blocked by Synta-1 (Supplementary information, Fig. S1c), a known blocker of the Orai1 channel, consistent with our previous report that the offresponse is mediated by Orai $1{ }^{28}$ However, the on-response was not blocked by Synta-1, indicating the involvement of other $\mathrm{Ca}^{2+}$-permeable channels (Supplementary information, Fig. S1c and see below Fig. 3). These data suggest that the characteristic STIM1-dependent heat off-response exists in native keratinocytes.

We next obtained STIM1-deficient mice that were generated from a gene trap embryonic stem (ES) cell line 335A11 containing an insertional disruption in the STIM1 gene, and cultured primary keratinocytes derived from WT, STIM1 $1^{+/-}$(Het) or STIM1 ${ }^{-/-}$(KO) littermate newborn mice. The antibody against the $\mathrm{N}$-terminus of STIM1 recognized a $\sim 86 \mathrm{kD}$ protein in keratinocytes cultured from WT but not STIM1 $1^{-1-} \mathrm{KO}$ mice (Fig. 1d). A decrease in STIM1 protein expression was observed in keratinocytes from STIM1 $1^{+/-}$heterozygous mice (Fig. 1d), consistent with previous reports on characterizing STIM1 expression in skeletal muscle cells. ${ }^{41}$ Cultured keratinocytes from WT mice showed store depletioninduced SOCE activity, which was virtually absent in $\mathrm{KO}$ keratinocytes (Fig. 1e, f). Keratinocytes from WT littermates showed strong responses to heat in single-cell $\mathrm{Ca}^{2+}$ imaging using the ratio metric $\mathrm{Ca}^{2+}$ dye Fura-2, both during and after heating as heat on- and off-responses, respectively (Fig. 1g, h), consistent with the Fluo-3 measurement of population cells using FLIPR (Fig. 1b). These responses were abolished in the absence of extracellular $\mathrm{Ca}^{2+}$ (Supplementary information, Fig. S1d). Strikingly, both the heat on- and off-responses were impaired in Het 

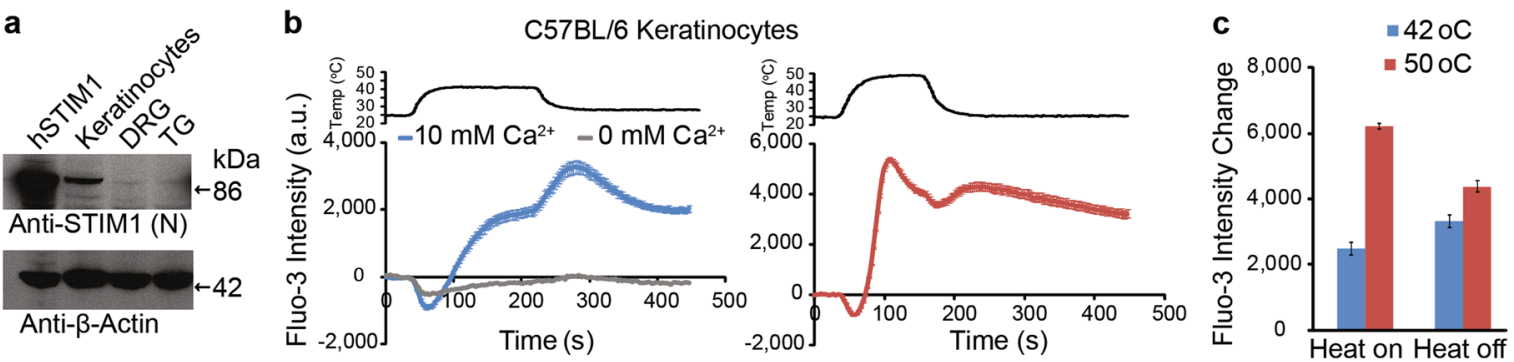

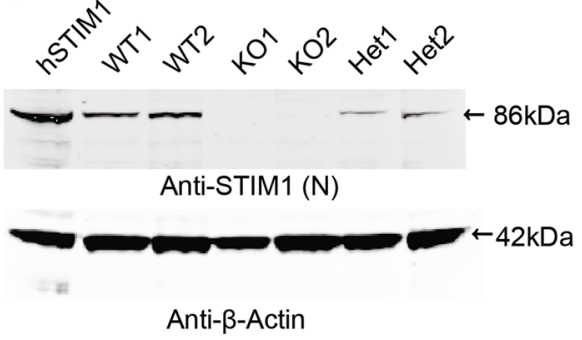

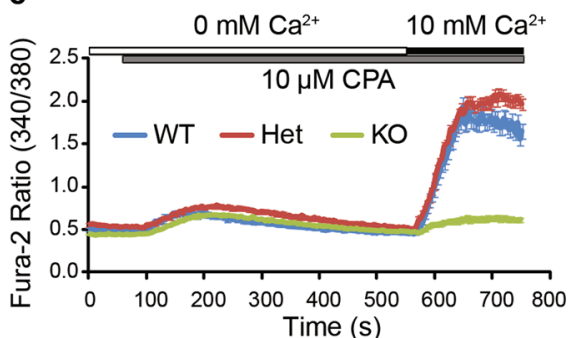

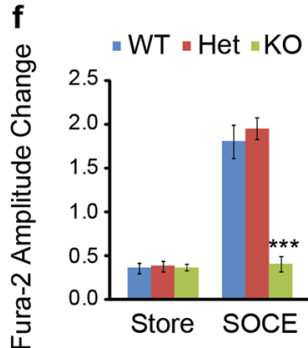

$\mathbf{g}_{0}$
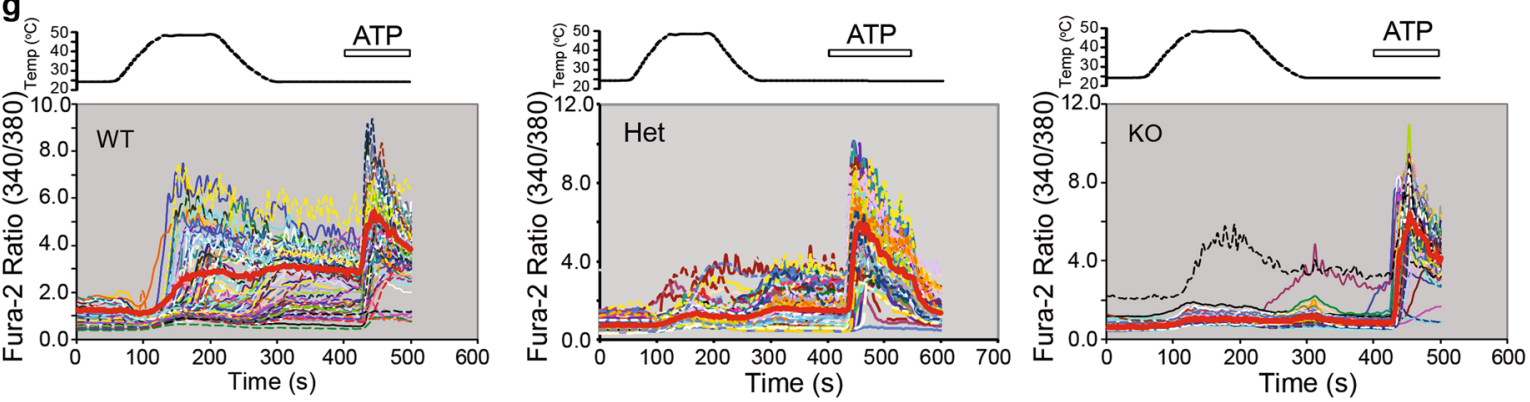

h

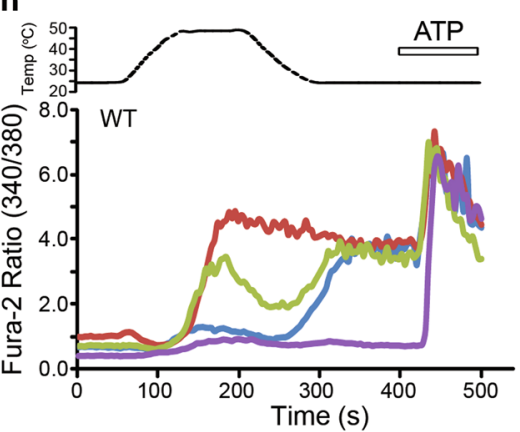

i
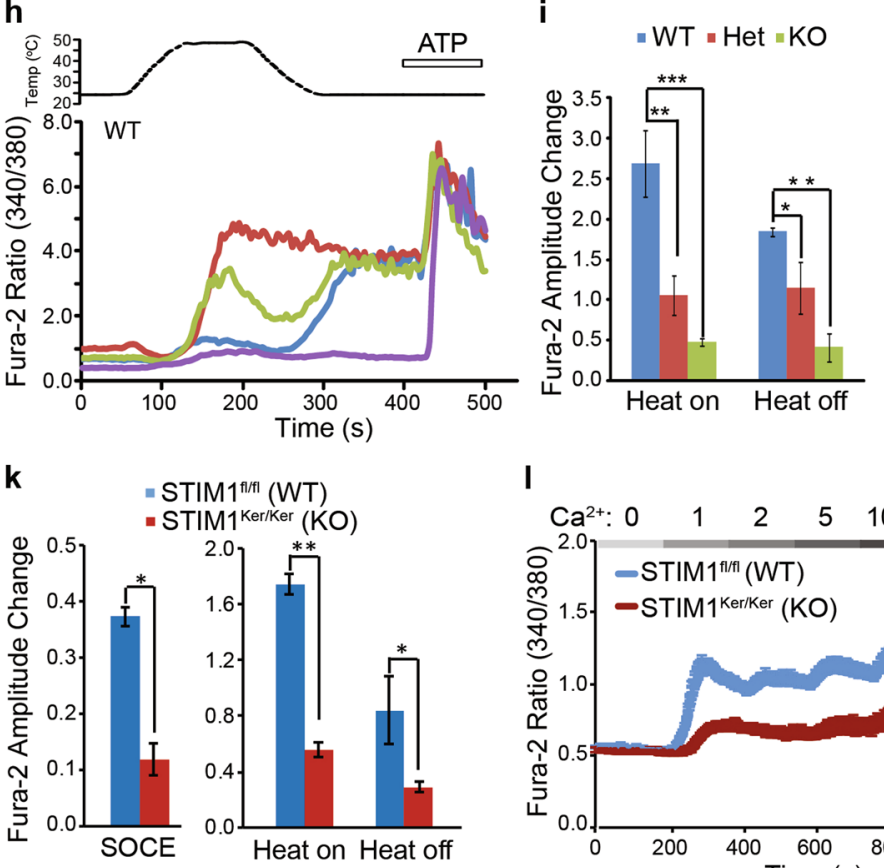

J
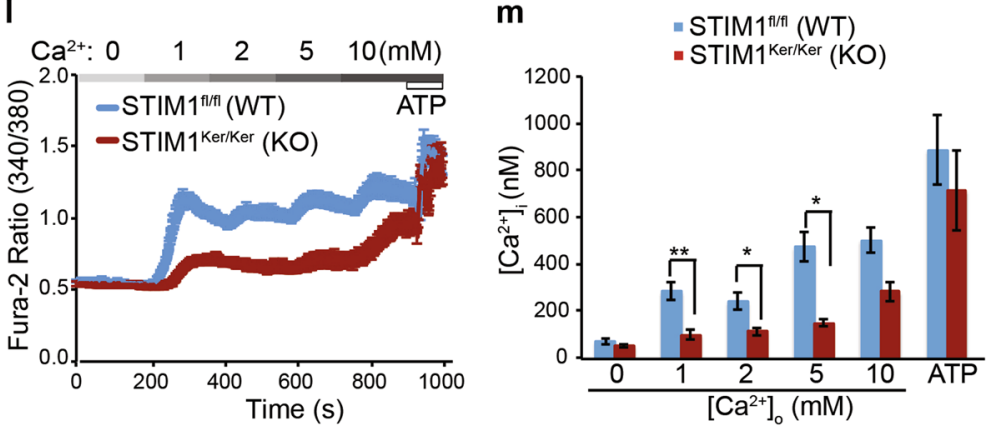

keratinocytes and further reduced in KO keratinocytes (Fig. 1g-i). The observation that the Het keratinocytes had normal SOCE but significantly impaired temperature responses indicates that the expression level of STIM1 might differentially affect the two processes. Our previous study has shown that only a portion of the heat-induced STIM1 puncta (an indication of STIM1 activation) remains in an aggregated state during the cooling phase for inducing Orai1-mediated heat off-response. ${ }^{28}$ Thus, it is likely that the STIM1-mediated temperature response is stringently dependent on the expression level of STIM1. We used ATP after the heat treatment as a control for cell viability and normal function of other $\mathrm{Ca}^{2+}$ signaling pathways in keratinocytes, and observed no 
Fig. 1 STIM1-dependent temperature responses in primary mouse keratinocytes. a Western blot of STIM1 and $\beta$-actin proteins of cell lysates derived from HeLa cells overexpressing human STIM1 $(30 \mu \mathrm{g})$, keratinocytes $(30 \mu \mathrm{g})$, DRG $(50 \mu \mathrm{g})$, and TG $(50 \mu \mathrm{g})$. The experiment was repeated three times. b Average baseline-subtracted Fluo-3 intensity of keratinocytes derived from C57BL/6 newborn mice in response to a heating pulse to $\sim 42^{\circ} \mathrm{C}$ (left panel) or $\sim 50{ }^{\circ} \mathrm{C}$ (right panel) measured by FLIPR. c Fluo-3 intensity changes of the heat on- and off-responses averaged from 4 individual wells. d Western blot of STIM1 and $\beta$-actin proteins of cell lysates derived from keratinocytes cultured from mice with the indicated genotypes. Cell lysates derived from human STIM1-overexpressing HeLa cells were used for positive control. The experiment was repeated three times. e Representative average traces of the indicated keratinocytes for SOCE measurement using single-cell Fura-2 ratiometric $\mathrm{Ca}^{2+}$ imaging. f Average Fura- 2 amplitude changes of ER $\mathrm{Ca}^{2+}$ store levels and SOCE from WT ( $n=3$ coverslips), Het ( $n=3$ coverslips) and KO keratinocytes ( $n=4$ coverslips). One-way ANOVA with Dunn's comparison to WT. ${ }^{* * *} P<0.001$. g Representative single-cell $\mathrm{Ca}^{2+}$ imaging of keratinocytes derived from STIM1 WT mice (158 cells), Het mice (135 cells) or STIM1 KO mice (168 cells), showing the response to heat and ATP. The bold red trace is the average response. $100 \mu \mathrm{M}$ ATP was applied at the end of the experiment for assaying cell viability. $\mathbf{h}$ Four representative WT cells derived from the left panel of $\mathbf{g}$ showing distinct temperature responses. Cells showing temperature response represented by red and green traces were counted as heat-responding cells, whereas those showing response represented by blue and green traces were counted as heat off-responding cells. i Fura-2 amplitude changes of keratinocytes obtained from WT ( $n=11$ coverslips from 6 mice), Het ( $n=10$ coverslips from 7 mice) and KO ( $n=6$ coverslips from 5 mice). Experiments with keratinocytes from Het and KO mice always included WT littermates. One-way ANOVA with Dunn's comparison to WT. ${ }^{*} P<0.05,{ }^{*} P<0.01,{ }^{* *} P<0.001$. j Immunofluorescent staining of skin specimens with the anti-STIM1 antibody. EP epidermal layer; HF hair follicles; ARP arrector pili muscle. The experiment was repeated three times. $\mathbf{k}$ The Fura-2 amplitude changes of SOCE, heat on- and off-responses of keratinocytes obtained from STIM $1^{\mathrm{f} / \mathrm{fl}}$ (WT) or STIM $1^{\mathrm{Ker} / \mathrm{Ker}}$ (KO) mice. Unpaired Student's $t$-test. ${ }^{*} P<0.05,{ }^{* *} P<0.01$. I Representative average traces of the indicated keratinocytes in response to the various concentrations of $\left[\mathrm{Ca}^{2+}\right]_{0}$ at room temperature. $100 \mu \mathrm{M}$ ATP was applied at the end of the experiment for assaying cell viability. $\mathbf{m}$ Average intracellular $\mathrm{Ca}^{2+}$ concentrations under the indicated concentrations of $\left[\mathrm{Ca}^{2+}\right]_{0}$. Unpaired Student's $t$-test. ${ }^{*} P<0.05,{ }^{* *} P<0.01$

difference in the percentage of ATP-responding cells among WT, Het and KO cells $(90.5 \% \pm 1.7 \%$ (WT, $n=11$ coverslips) vs $86.3 \% \pm$ $2.9 \%$ (KO, $n=6$ coverslips) vs $90.1 \% \pm 1.9 \%$ (Het, $n=10$ coverslips)). TRPV3- and TRPV4-dependent heat responses have been electrophysiologically recorded from primary keratinocytes. ${ }^{22,42}$ However, the keratinocyte heat-induced $\mathrm{Ca}^{2+}$ signals were normal in TRPV $3^{-/} / \mathrm{TRVP}^{-/-}$double knockout mice (Supplementary information, Fig. S1e, f). These results suggest that TRPV3 and TRPV4 did not account for the observed heat-induced $\mathrm{Ca}^{2+}$ influx in keratinocytes.

Most of the constitutive STIM1 KO mice died perinatally, precluding us from carrying out behavioral analysis of these mice. To specifically characterize the physiological significance of STIM1 expression in keratinocytes, we generated keratinocyte-specific

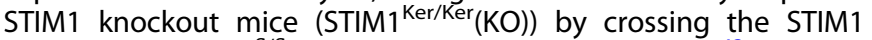
floxed mice $\left(\mathrm{STIM} 1^{\mathrm{f} / \mathrm{fl}}\right.$ in $\mathrm{C} 57 \mathrm{BL} / 6$ genetic background) ${ }^{43}$ with the $\mathrm{K} 14-\mathrm{Cre}$ mice (in a B6CBA mixed genetic background) engineered to express Cre recombinase in keratinocytes. ${ }^{44} \mathrm{STIM} 1{ }^{\mathrm{Ker} / \mathrm{Ker}}(\mathrm{KO})$ mice did not display obvious morphological defects in the skin (Supplementary information, Fig. S1g) and had similar body weight $\left(26.4 \pm 0.4 \mathrm{~g}\right.$ and $25.8 \pm 0.6 \mathrm{~g}$ for STIM $1^{\mathrm{fl} / \mathrm{fl}}(\mathrm{WT})$ and STIM $1{ }^{\mathrm{Ker} / \mathrm{Ker}}(\mathrm{KO})$, respectively) and internal body temperature to $\mathrm{STIM} 1^{\mathrm{fl} / \mathrm{fl}}(\mathrm{WT})$ mice $\left(37.3{ }^{\circ} \mathrm{C} \pm 0.1{ }^{\circ} \mathrm{C}\right.$ and $37.2^{\circ} \mathrm{C} \pm 0.1^{\circ} \mathrm{C}$ for STIM $1^{\mathrm{fl} / \mathrm{fl}}(\mathrm{WT})$ and $\mathrm{STIM}{ }^{\mathrm{Ker} / \mathrm{Ker}}(\mathrm{KO})$, respectively). Immunofluorescent staining of skin tissues derived from STIM $1^{\mathrm{Ker} / \mathrm{Ker}}(\mathrm{KO})$ mice showed that STIM1 was specifically deleted in the epidermal layer, but not in other cell types residing in the skin such as arrector pili (ARP) muscle cells (Fig. 1j). Western blotting also showed that the STIM1 protein was depleted in keratinocytes derived from STIM1 ${ }^{\mathrm{Ker} / \mathrm{Ker}}(\mathrm{KO})$ mice (Fig. 2d). Consistent with the results obtained from STIM1 ${ }^{-/-}$ keratinocytes (Fig. 1g-i), primary keratinocytes cultured from neonatal STIM1 ${ }^{\text {Ker/Ker }}(\mathrm{KO})$ mice had impaired SOCE and defective heat on- and off-responses (Fig. 1k). Keratinocytes cultured from adult STIM $1^{\mathrm{f} / \mathrm{fl}}$ (WT) and STIM1 ${ }^{\mathrm{Ker} / \mathrm{Ker}}$ (KO) mice also showed STIM1dependent heat on- and off-responses (Supplementary information, Fig. S1h). Furthermore, switching STIM1 $1^{\mathrm{fl} / \mathrm{fl}}$ (WT) keratinocytes from $\mathrm{Ca}^{2+}$-free buffer to $\mathrm{Ca}^{2+}$-containing buffer resulted in a significant $\mathrm{Ca}^{2+}$ influx, which was greatly reduced in STIM1 ${ }^{\mathrm{Ker} /}$ ${ }^{\mathrm{Ker}}(\mathrm{KO})$ keratinocytes (Fig. 1l, m), consistent with a previous report showing that knockdown of STIM1 in human keratinocytes abolishes such $\mathrm{Ca}^{2+}$ switch-induced $\mathrm{Ca}^{2+}$ responses. ${ }^{34}$ Owing to the small endogenous STIM1-mediated CRAC current ( 0.5 pA/ $\mathrm{pF})^{34}$ and the presence of relatively large TRPV3- and TRPV4mediated temperature-induced currents $(\sim 10-20 \mathrm{pA} / \mathrm{pF}),{ }^{42}$ we could not characterize the electrophysiological properties of the STIM1-dependent temperature responses. Nevertheless, our data suggest that STIM1 mediates temperature-induced and basal $\mathrm{Ca}^{2+}$ influx in keratinocytes.

STIM1 thermosensitivity determines temperature-induced $\mathrm{Ca}^{2+}$ responses in keratinocytes

We have previously shown that the C-terminal K-domain of STIM1 is critical for its thermosensitivity, but largely dispensable for the store depletion-induced response. ${ }^{28}$ To further investigate whether the role of STIM1 in mediating temperature-induced $\mathrm{Ca}^{2+}$ responses in keratinocytes is specifically due to its temperature sensitivity rather than its $\mathrm{ER} \mathrm{Ca}^{2+}$ sensing capability, we generated a STIM1- $\Delta \mathrm{K}$ knock-in mice by introducing a stop codon in exon 12 of the STIM1 gene, resulting in deletion of the C-terminal K-domain (STIM1- $\Delta \mathrm{K}$ mice) (Fig. 2a-C). Using STIM1 antibodies specifically recognizing either the $\mathrm{N}$-terminal or the C-terminal domain of STIM1, we found that the STIM1 protein derived from STIM1- $\Delta \mathrm{K}$ keratinocytes was specifically recognized by the $\mathrm{N}$-terminal antibody, but not by the C-terminal antibody (Fig. 2d). The STIM1 protein from WT but not from STIM1 ${ }^{\text {Ker/Ker (KO) }}$ keratinocytes was recognized by both antibodies (Fig. $2 \mathrm{~d}$ ). These data demonstrate that the STIM1- $\Delta \mathrm{K}$ mutant mice successfully express the STIM1- $\Delta \mathrm{K}$ mutant proteins. STIM1- $\Delta \mathrm{K}$ mice were viable with normal body temperature (rectal temperature of $38.2^{\circ} \mathrm{C} \pm$ $0.1{ }^{\circ} \mathrm{C}$ vs $38.0^{\circ} \mathrm{C} \pm 0.1{ }^{\circ} \mathrm{C}$ for WT and STIM $1-\Delta \mathrm{K}$ mice, respectively), and had no obvious morphological defects in the skin (Supplementary information, Fig. S2).

Consistent with our previous observation that the K-domain of STIM1 is partially dispensable for SOCE, ${ }^{28}$ keratinocytes derived from STIM1- $\Delta \mathrm{K}$ mice retained a larger portion of SOCE compared to $S T I M 1^{\mathrm{Ker} / \mathrm{Ker}}(\mathrm{KO})$ keratinocytes (Fig. 2e). The relatively normal SOCE of the cells derived from STIM1- $\Delta \mathrm{K}$ mice is consistent with the observation that these mice were born with expected Mendelian inheritance ratio, in contrast to the constitutive $S T I M 1^{-/-}$KO mice. On the other hand, both the heat on- and offresponses of STIM1- $\Delta \mathrm{K}$ keratinocytes were impaired to the same extent as that of STIM1 ${ }^{\mathrm{Ker} / \mathrm{Ker}}(\mathrm{KO})$ keratinocytes (Fig. 2f). Interestingly, the STIM1-mediated basal $\mathrm{Ca}^{2+}$ influx also depends on temperatures within the warm temperature zone (Fig. $2 \mathrm{~g}$ ). Upon switching from $0 \mathrm{mM}$ to $2 \mathrm{mM}\left[\mathrm{Ca}^{2+}\right]_{\mathrm{o}}$, WT keratinocytes had a bell-shaped basal $\mathrm{Ca}^{2+}$ influx from $26^{\circ} \mathrm{C}$ to $42^{\circ} \mathrm{C}$ with a peak response at $30^{\circ} \mathrm{C}$ and $33^{\circ} \mathrm{C}$ (Fig. 2g), which was drastically reduced in STIM $1^{\mathrm{Ker} / \mathrm{Ker}}(\mathrm{KO})$ keratinocytes (Fig. $2 \mathrm{~g}$ ). Importantly, the temperature-dependent basal $\mathrm{Ca}^{2+}$ influx was also significantly impaired in STIM1- $\triangle \mathrm{K}$ keratinocytes ranging from $26^{\circ} \mathrm{C}$ to $37^{\circ} \mathrm{C}$ (Fig. 2g). Notably, both STIM $1^{\mathrm{Ker} / \mathrm{Ker}}(\mathrm{KO})$ and STIM- $\Delta \mathrm{K}$ keratinocytes had higher basal $\mathrm{Ca}^{2+}$ influx at $42^{\circ} \mathrm{C}$, indicating 

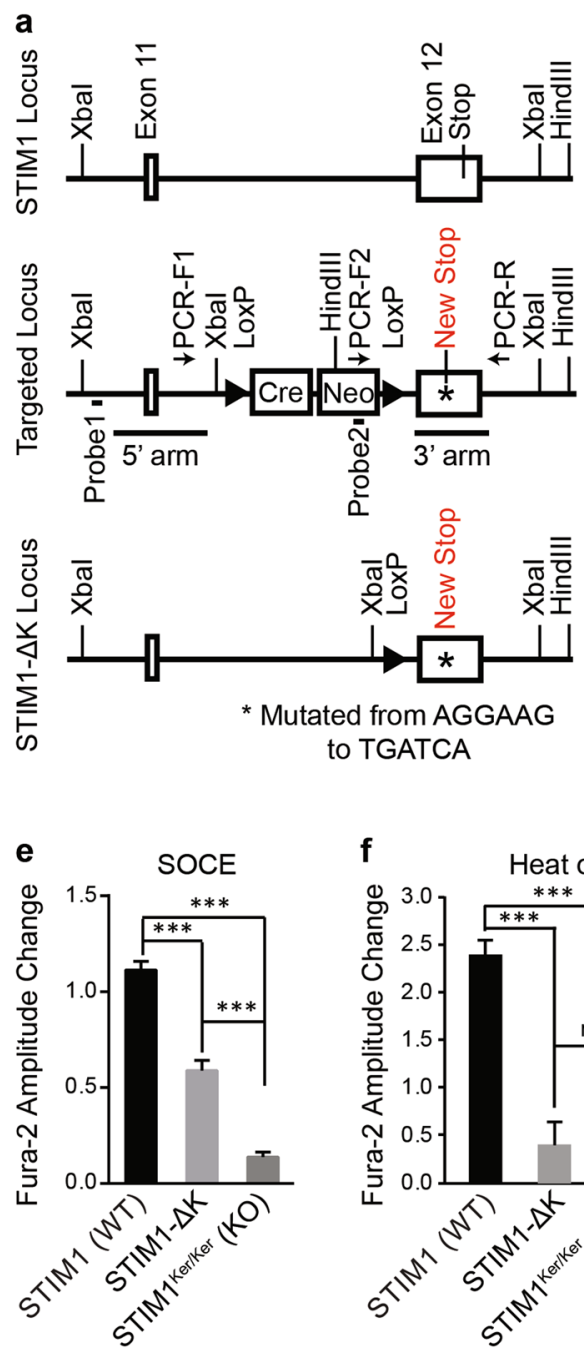

b

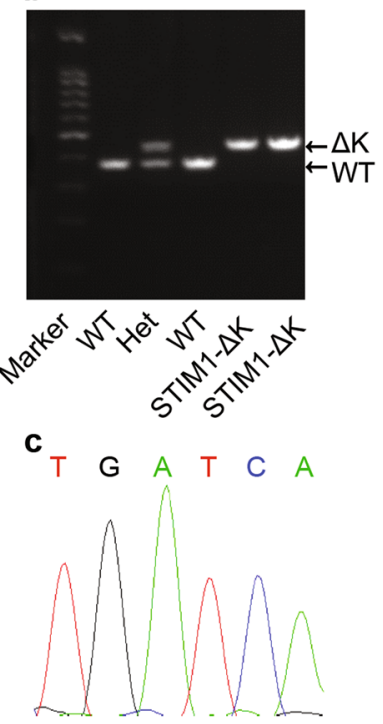

d

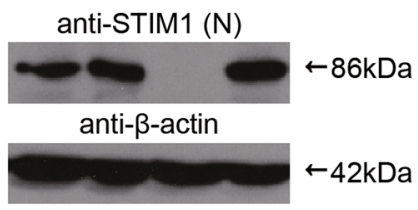

anti-STIM1 (C)

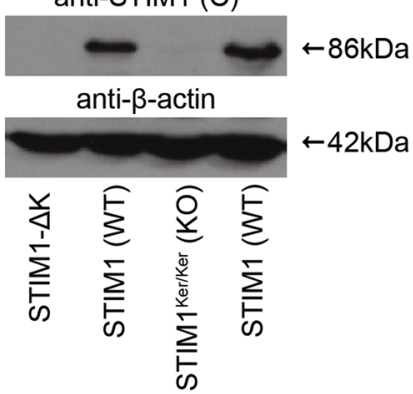

g Ca ${ }^{2+}$ influx upon $0 \mathrm{mM}$ to $2 \mathrm{mM}\left[\mathrm{Ca}^{2+}\right]_{0}$
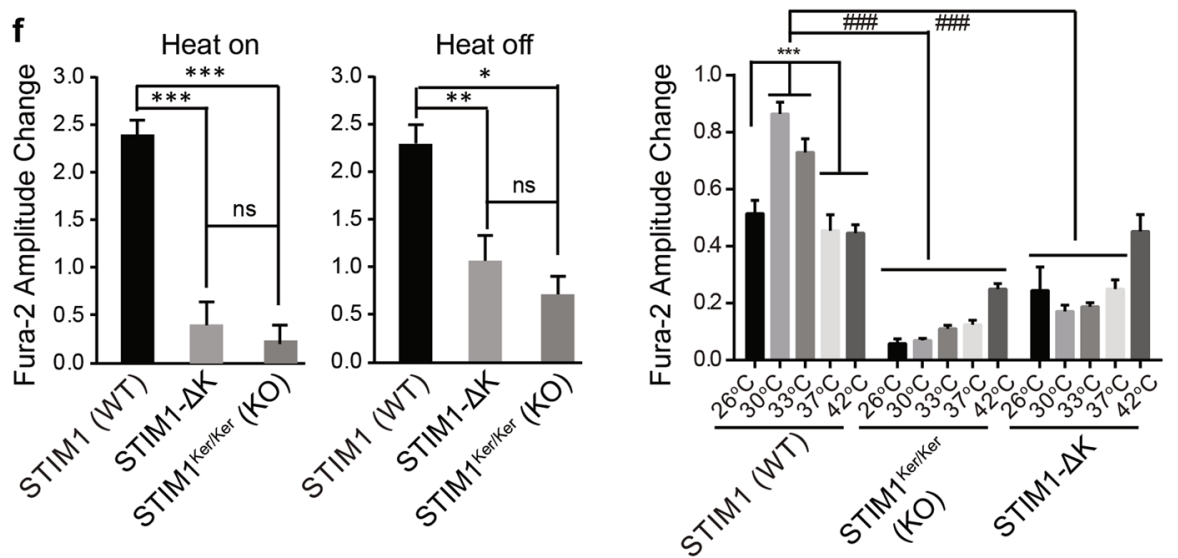

Fig. 2 Generation and characterization of the STIM1- $\Delta \mathrm{K}$ knock-in mice. a Schematic illustration of the strategy for generating the STIM1- $\Delta \mathrm{K}$ knock-in mice. A testes-specific promoter (tACE promoter) driven expression of Cre resulted in self-excision of the Cre-Neo cassette during spermatogenesis. b Genotyping of the indicated mice using PCR. c Sequencing validation of the designated nucleotide change derived from the STIM1- $\Delta \mathrm{K}$ genome. d Western blotting with the indicated STIM1 antibodies for confirming the expression of the expected STIM1- $\Delta \mathrm{K}$ truncated protein in keratinocytes derived from STIM1- $\Delta \mathrm{K}$ knock-in mice. Keratinocytes derived from the STIM1 ${ }^{\mathrm{Ker} / \mathrm{Ker}}$ (KO) mice showed no STIM1 expression. The experiment was repeated three times. e SOCE responses of the indicated keratinocytes $(n=3,8,7$ coverslips for STIM1 (WT), STIM1- $\Delta \mathrm{K}$ and STIM1 ${ }^{\mathrm{Ker} / \mathrm{Ker}}(\mathrm{KO})$ mice, respectively). One-way ANOVA with multiple comparisons. ${ }^{* * *} P<0.001$. f Heat on- and offresponses of the indicated keratinocytes $(n=26,16$ and 4 coverslips for STIM1(WT), STIM1- $\Delta$ K and STIM1 Ker/Ker (KO) mice, respectively). The STIM1-independent temperature-induced change of the Fura-2 signal itself was subtracted (see Methods). One-way ANOVA with multiple comparisons. ${ }^{*} P<0.05,{ }^{* *} P<0.05,{ }^{* * *} P<0.001$. g Average Fura- 2 amplitude changes of the indicated keratinocytes under the indicated bath temperatures upon switching $\left[\mathrm{Ca}^{2+}\right]_{0}$ from $0 \mathrm{mM}$ to $2 \mathrm{mM}$. WT: $n=11,13,22,14$ and 5 coverslips; STIM1 ${ }^{\mathrm{Ker} / \mathrm{Ker}}(\mathrm{KO}): n=3,4,8,7$ and 3 coverslips; STIM1- $\Delta \mathrm{K}: n=6,5,6,7$ and 4 coverslips for $26^{\circ} \mathrm{C}, 30^{\circ} \mathrm{C}, 33^{\circ} \mathrm{C}, 37^{\circ} \mathrm{C}$ and $42^{\circ} \mathrm{C}$, respectively). ANOVA with multiple comparisons among the various temperatures within the STIM1(WT) sample, ${ }^{* * *} P<0.001$. One-way ANOVA with Dunn's comparison between STIM1(WT), $\mathrm{STIM} 1^{\mathrm{Ker} / \mathrm{Ker}}(\mathrm{KO})$ and STIM1- $-\mathrm{K}$ at the corresponding temperatures (e.g., STIM1(WT) at $26^{\circ} \mathrm{C}$ vs STIM $1^{\mathrm{Ker} / \mathrm{Ker}}(\mathrm{KO})$ at $26^{\circ} \mathrm{C}$ ), \#\#\#P<0.001

the potential involvement of other ion channels (Fig. $2 \mathrm{~g}$ ). Collectively, these data demonstrate that the STIM1 thermosensitivity mediates acute heat-induced on- and off-responses and basal $\mathrm{Ca}^{2+}$ influx within the warm temperature range in primary keratinocytes.

Orai1 and Orai3 mediate STIM1-dependent temperature responses

STIM1 (Supplementary information, Fig. S3a), ${ }^{28}$ but not its homologue STIM2 (Supplementary information, Fig. S3b), mediates the characteristic heat off-response when co-expressed with Orai1. Given that keratinocytes have STIM1-dependent heat onand off-responses, we asked whether other isoforms of the Orai channel family, including Orai2 and Orai3, might mediate STIM1dependent temperature responses. Intriguingly, we found that Orai3 (Fig. 3a-f), but not Orai2 (Supplementary information, Fig. S3a), could mediate STIM1-dependent heat on- and offresponses. HeLa cells overexpressing GFP-STIM1 and Orai3 displayed both heat on- and off-responses (Fig. $3 a$ and Supplementary information, Fig. S3c). The heat on-response was more robust at higher temperatures $\left(48^{\circ} \mathrm{C}\right.$ compared to $41^{\circ} \mathrm{C}$, Supplementary information, Fig. S3c). Nevertheless, no heat response was observed in HeLa cells when Orai3 was coexpressed with either STIM1- $\Delta \mathrm{K}$ (which lacks heat sensitivity) ${ }^{28}$ (Fig. 3b) or STIM1- $\triangle$ CAD (which is defective in interacting with and activating Orai channels) (Fig. 3c). This demonstrates the 

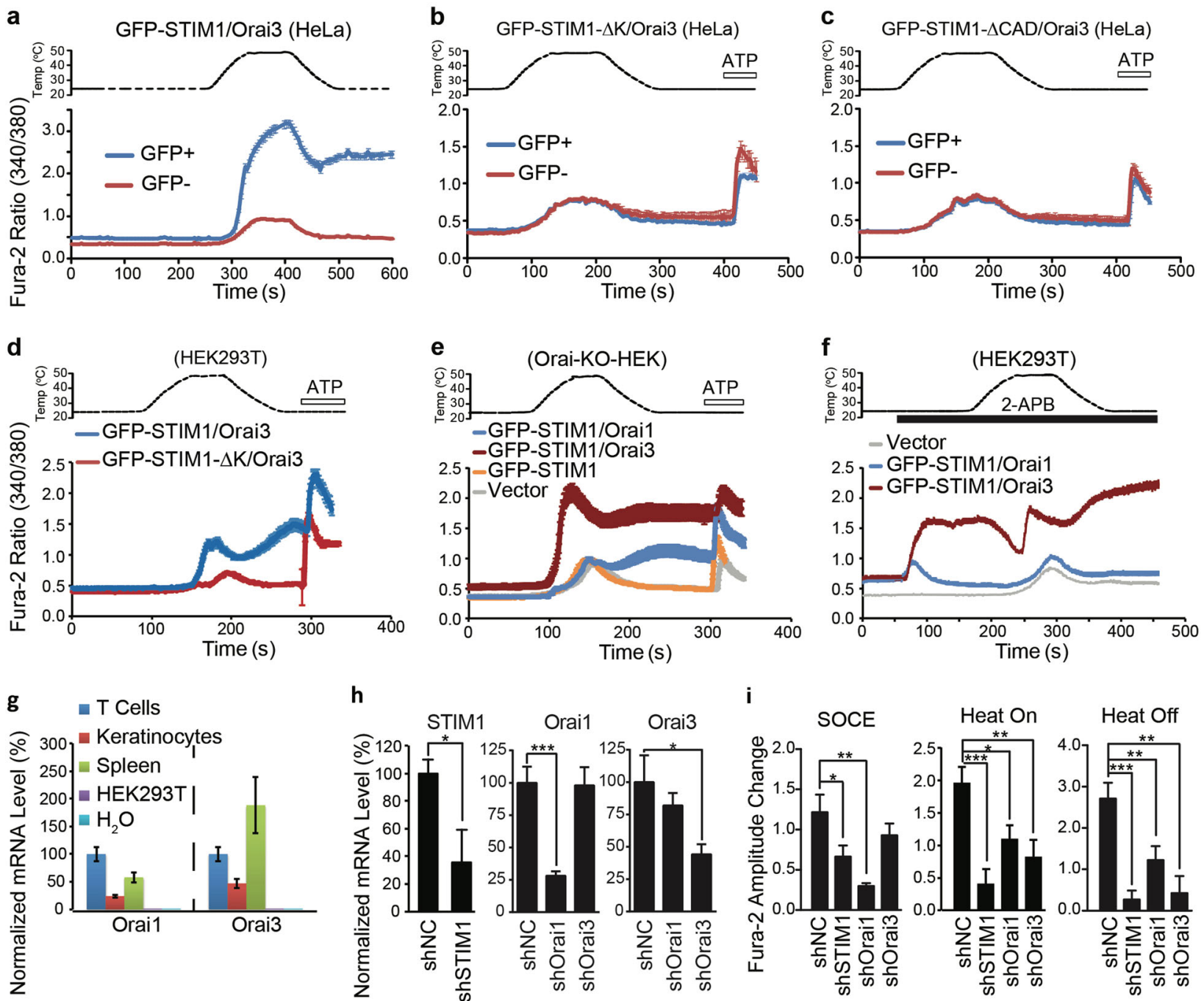

Fig. 3 Orai1 and Orai3 mediate STIM1-dependent temperature responses. a-c Average Fura-2 ratio of GFP ${ }^{+}$and GFP ${ }^{-}$HeLa cells transfected with the indicated constructs in response to a heating pulse to $\sim 50{ }^{\circ} \mathrm{C}$ in the presence of $10 \mathrm{mM}\left[\mathrm{Ca}^{2+}\right]_{\mathrm{o}}$. $\mathbf{d ~ A v e r a g e ~ F u r a - 2 ~ r a t i o ~ o f ~}$ HEK293T cells transfected with the indicated constructs in response to a heating pulse to $\sim 50^{\circ} \mathrm{C}$ in the presence of $10 \mathrm{mM}\left[\mathrm{Ca}{ }^{2+}\right]_{0}$. e Average Fura-2 ratio of the Orai-KO-HEK cells, in which the endogenous Orai1, Orai2 and Orai3 genes were all knocked out, transfected with the indicated constructs in response to a heating pulse to $\sim 50{ }^{\circ} \mathrm{C}$ in the presence of $2 \mathrm{mM}\left[\mathrm{Ca}^{2+}\right]_{0}$. $f$ Average Fura- 2 ratio of $\mathrm{HEK} 293 \mathrm{~T}$ cells transfected with the indicated constructs in response to a heating pulse to $\sim 50^{\circ} \mathrm{C}$ in the presence of $50 \mu \mathrm{M} 2$-APB. g mRNA levels of Orai 1 and Orai3 from the indicated cell types or tissues were normalized to that of T cells. Each condition has three replicates. $\mathbf{h}$ Knockdown efficiency of the indicated shRNAs $(n=11,4,10,10$ for shNC, shSTIM1, shOrai1 and shOrai3 from three independent experiments, respectively. One-way ANOVA with Dunn's comparison to shNC. ${ }^{*} P<0.05$, ${ }^{* *} P<0.01$ ). i Summary of SOCE, heat on- and off-responses of keratinocytes obtained from the indicated conditions ( $n=6-10$ coverslips). The STIM1-independent temperature-induced change of the Fura-2 signal itself was subtracted (see Methods). One-way ANOVA with Dunn's comparison to shNC. ${ }^{*} P<0.05,{ }^{* *} P<0.01$, ${ }^{* * *} P<0.001$

dependence of STIM1 temperature sensitivity and functional coupling with Orai3. Similar heat on- and off-responses were also observed in HEK293T cells co-transfected with GFP-STIM1 and Orai3 (Fig. 3d), but not in cells co-transfected with GFP-STIM1- $\Delta \mathrm{K}$ and Orai3 (Fig. 3d) or transfected with Orai3 and GFP or GFPSTIM1 alone (Supplementary information, Fig. S3d).

To exclude the possibility that the off-response observed in STIM1/Orai3-transfected cells is due to endogenously expressed Orai channels, we utilized both the Orai1-KO-HEK cells and OraiKO-HEK cell lines, in which the Orai1 gene alone or all three Orai genes were depleted, respectively. ${ }^{45,46}$ Importantly, in both cell lines, co-expression of STIM1 and Orai1 specifically generated the heat off-response, whereas co-expression of STIM1 and Orai3 gave rise to both heat on- and off-responses (Fig. 3e and Supplementary information, Fig. S3e). Cells transfected with STIM1 or vector did not produce the heat responses (Fig. 3e and Supplementary information, Fig. S3e). We further tested the effect of 2aminoethoxydiphenylborane (2-APB) on the distinct temperature responses mediated by Orai1 and Orai3 as 2-APB has differential effects on Orai1 and Orai3. The store-operated STIM1/Orai1 activity is inhibited, whereas the STIM1/Orai3 activity is potentiated by 2-APB at a concentration of $50 \mu \mathrm{M} .{ }^{47}$ Furthermore, 2-APB can robustly activate Orai3, but only cause weak activation of Orai1 in a STIM1- and store-independent way. ${ }^{47}$ Indeed, $50 \mu \mathrm{M} 2$ 2APB induced a robust and sustained increase of $\mathrm{Ca}^{2+}$ in STIM1/ Orai3-transfected HEK293T cells, but only a small and transient $\mathrm{Ca}^{2+}$ response in STIM1/Orai1-transfected cells (Fig. 3f). No 2-APB response was observed in vector-transfected cells (Fig. 3f). Interestingly, in the presence of $50 \mu \mathrm{M} 2$-APB, the STIM1/Orai1mediated heat off-response was completely prevented (Fig. 3f). For STIM1/Orai3-transfected cells, heating first caused a drop of the sustained 2-APB-induced response (the mechanism 
underlying this phenomenon is currently unclear), then an abrupt rise of the Fura-2 signal at high temperatures, followed by an apparent off-response upon cooling (Fig. 3f). When applied after the occurrence of the heat off-response during the cooling phase, 2-APB only blocked STIM1/Orai1-, but not STIM1/Orai3-mediated off-response (Supplementary information, Fig. S3f). Thus, 2-APB effectively blocked Orai1-mediated off-response, but did not affect STIM1/Orai3-mediated heat on- and off-responses. Collectively, these data demonstrate that Orai 1 and Orai3 sufficiently and distinctly mediate the STIM1-dependent temperature responses in heterologous cells.

We next went on to examine the involvement of Orai1 and Orai3 in STIM1-dependent temperature responses in primary keratinocytes. A significant amount of Orai1 and Orai3 were detected in keratinocytes by RT-PCR (Fig. 3g). We employed lentivirus infection of shRNAs against STIM1, Orai1 and Orai3, respectively, to knock down their expression in keratinocytes (Fig. 3h). As a positive control, knockdown of STIM1 resulted in a significant reduction of SOCE and heat on- and off-responses in keratinocytes (Fig. 3i). The shRNA against Orai1 or Orai3 specifically knocked down the expression of Orai1 or Orai3, but did not cause non-specific knockdown of Orai3 or Orai1, respectively (Fig. 3h). Knockdown of Orai1 led to decreased SOCE and heat on- and offresponses (Fig. 3i), suggesting the requirement of Orai1 for both heat on- and off-responses (Fig. 3i). Intriguingly, knockdown of Orai3 also reduced heat on- and off-responses, but not SOCE (Fig. 3i). Given that STIM1/Orai1 only mediates heat off-response, whereas STIM1/Orai3 is sufficient to mediate both heat on- and off-responses in heterologous cell lines, one possibility is that Orai1 and Orai3 might form heteromeric channels in keratinocytes, which can mediate both heat on- and off-responses. Previous studies of endothelial cells have proposed the existence of Orai1-Orai3 heteromeric channels, which have properties distinct from Orai1 or Orai3 homomeric channels. ${ }^{48,49}$ Regardless of the exact nature of the Orai 1 and Orai3 channels that exist in keratinocytes, our data have demonstrated that STIM1 can mediate distinct temperature responses by coupling to Orai1 and Orai3.

Keratinocyte-specific, but not neuron-specific STIM1-knockout mice display altered thermotaxis behaviors

We initially carried out behavioral analysis of $\mathrm{STIM} 1^{\mathrm{f} / / \mathrm{f}}(\mathrm{WT})$ and $\mathrm{STIM} 1^{\mathrm{Ker} / \mathrm{Ker}}(\mathrm{KO})$ mice in a mixed genetic background as described above. When assayed on a temperature gradient apparatus that has varied floor temperatures ranging from $15^{\circ} \mathrm{C}$ to $54^{\circ} \mathrm{C}$ for $2 \mathrm{~h},{ }^{12}$ $\mathrm{STIM} 1^{\mathrm{fl} / \mathrm{f}}(\mathrm{WT})$ mice gradually gravitated towards warm temperature zones and eventually settled around the temperature zone of $\sim 32^{\circ} \mathrm{C}$ (Fig. 4a), the expected optimal preference temperature (OPT) for WT mice. Interestingly, STIM $1{ }^{\mathrm{Ker} / \mathrm{Ker}}(\mathrm{KO})$ littermates sought warm temperature zones much faster and settled to the warmer zones of $\sim 35^{\circ} \mathrm{C}$, resulting in an overall rightward shift of the temperature-sensing profile (Fig. 4a). These data indicate that STIM $1^{\mathrm{Ker} / \mathrm{Ker}}(\mathrm{KO})$ mice may have a specific deficit in defining the OPT.

To verify the altered behaviors of the $\mathrm{STIM} 1^{\mathrm{Ker} / \mathrm{Ker}}(\mathrm{KO})$ mice in sensing warm temperatures, we next subjected these mice to twotemperature choice assays at three testing paradigms covering the warm temperature range: $33^{\circ} \mathrm{C}$ vs $29^{\circ} \mathrm{C}, 37^{\circ} \mathrm{C}$ vs $33^{\circ} \mathrm{C}$ and $41^{\circ}$ $\mathrm{C}$ vs $37^{\circ} \mathrm{C}$, and analyzed the difference between STIM1 $1^{\mathrm{fl} / \mathrm{fl}}(\mathrm{WT})$ and $\mathrm{STIM} 1^{\mathrm{Ker} / \mathrm{Ker}}(\mathrm{KO})$ mice in occupying the warmer temperature side at different periods of the test (Fig. 4b-d). The ability of the STIM $1^{\text {fl/fl }}($ WT $)$ and STIM $1^{\text {Ker/Ker }}($ KO) mice to choose one of the two testing temperatures was also analyzed. The dotted line in the two temperature choice assay shown in Figs. 4-7 indicates no preference between the two temperatures and the statistic label "*" inside the data bar indicates that the mice significantly prefer one of the two testing temperatures. An alternative presentation of the data for Fig. $4 \mathrm{~b}-\mathrm{d}$ is shown in Supplementary information,
Fig. S4. When analyzed at $33^{\circ} \mathrm{C}$ vs $29^{\circ} \mathrm{C}$, STIM $1^{\text {fl/fl }}(\mathrm{WT})$ and $\mathrm{STIM} 1^{\mathrm{Ker} / \mathrm{Ker}}(\mathrm{KO})$ mice did not show significant difference in occupying the $33^{\circ} \mathrm{C}$ side as both preferred $33^{\circ} \mathrm{C}$ (Fig. 4b). Interestingly, while STIM $1^{\mathrm{f} / \mathrm{fl}}(\mathrm{WT})$ mice robustly preferred $33^{\circ} \mathrm{C}$ over $37^{\circ} \mathrm{C}$, STIM $1^{\mathrm{Ker} / \mathrm{Ker}}(\mathrm{KO})$ mice completely lost such preference and spent more time on the $37^{\circ} \mathrm{C}$ side than STIM1 $1^{\mathrm{fl} / \mathrm{fl}}$ (WT) (Fig. 4C). In contrast, when tested at $41^{\circ} \mathrm{C}$ vs $37^{\circ} \mathrm{C}$, both groups of mice indistinguishably preferred $37^{\circ} \mathrm{C}$ (Fig. 4d), indicating that the $\mathrm{STIM} 1^{\mathrm{f} / \mathrm{fl}}(\mathrm{WT})$ mice did not simply seek warmer temperatures in general.

To examine any involvement of STIM1 from primary sensory neurons in warm sensation despite its relatively low expression level (Fig. 1a) and potential lack of ER at the free nerve endings, we generated neuron-specific STIM1-deficient mice by crossing the STIM $1{ }^{\mathrm{fl} / \mathrm{fl}}$ mice with the Nestin-Cre mice engineered to express Cre recombinase in neurons $\left(\mathrm{STIM} 1^{\text {Nest/Nest }}(\mathrm{KO})\right.$ in pure $\mathrm{C} 57 \mathrm{BL} / 6$ background). When similarly subjected to the temperature gradient (Fig. 4e) or two-temperature choice assays (Fig. 4f-h), STIM1 $1^{\text {Nest/Nest }}\left(\right.$ KO) mice behaved the same as STIM1 ${ }^{\mathrm{f} / f \mathrm{f}}(\mathrm{WT})$ mice. Taken together, these data suggest that keratinocyte-originated STIM1 plays a specific role in defining the OPT and affecting warm preference behaviors.

The in vivo role of STIM1 in warm sensation is preserved in both male and female C57BL/6 mice

Mouse genetic background can substantially affect mouse behaviors. Previous studies have shown that keratinocyteexpressing TRPV3 may play a role in warm sensation in a mixed genetic background but not in the C57BL/ 6 background. ${ }^{22,24}$ Thus, we backcrossed the mice into a C57BL/6 background for ten generations and then examined their responses in twotemperature choice assays. At $37^{\circ} \mathrm{C}$ vs $33^{\circ} \mathrm{C}$, compared to the $\mathrm{STIM} 1^{\mathrm{fl} / \mathrm{fl}}(\mathrm{WT})$ in $\mathrm{C} 57 \mathrm{BL} / 6$ background $(\mathrm{WT}(\mathrm{B} 6))$, the littermate $\mathrm{STIM} 1^{\mathrm{Ker} / \mathrm{Ker}}(\mathrm{KO})$ mice $(\mathrm{KO}(\mathrm{B} 6))$ did not significantly distinguish between $37^{\circ} \mathrm{C}$ and $33^{\circ} \mathrm{C}$, and tended to spend more time in the $37^{\circ} \mathrm{C}$ side (Fig. 5a). Furthermore, the WT(B6) and $\mathrm{KO}(\mathrm{B} 6)$ behaved differently at other test paradigms including $36^{\circ} \mathrm{C}$ vs $32^{\circ} \mathrm{C}$ (Fig. 5 b), $38^{\circ} \mathrm{C}$ vs $30^{\circ} \mathrm{C}$ (Fig. $5 \mathrm{C}$ ) and $34^{\circ} \mathrm{C}$ vs $32^{\circ} \mathrm{C}$ (Fig. 5e).

We also examined the preference profiles of female mice, which behaved differently from male mice. For instance, while male mice preferred $33^{\circ} \mathrm{C}$ over $37^{\circ} \mathrm{C}$ (Fig. 5a), female mice behaved oppositely by slightly preferring $37^{\circ} \mathrm{C}$ over $33^{\circ} \mathrm{C}$ (Supplementary information, Fig. S5b), suggesting that female mice normally prefer warmer temperatures than male mice. Compared to female WT(B6), female $\mathrm{KO}(\mathrm{B} 6)$ mice showed similar preference profiles at both testing paradigms of $33^{\circ} \mathrm{C}$ vs $29^{\circ} \mathrm{C}$ and $37^{\circ} \mathrm{C}$ vs $33^{\circ} \mathrm{C}$ (Supplementary information, Fig. S5a, b), but completely lost their ability to distinguish between $41^{\circ} \mathrm{C}$ and $37^{\circ} \mathrm{C}$ (Supplementary information, Fig. S5c). The female $\mathrm{KO}(\mathrm{B} 6)$ mice spent significantly more time at the $41{ }^{\circ} \mathrm{C}$ side (Supplementary information, Fig. S5C). Taken together, these data demonstrate that STIM1 plays a critical role in determining the warm preference behaviors of mice regardless of their genetic background and sex. We focused on using male mice in the C57BL/6 background for the subsequent studies shown below.

Despite the robust STIM1-dependent acute heat on- and offresponses of $\mathrm{Ca}^{2+}$ when heated to high temperatures (Fig. 1), the male $\mathrm{KO}(\mathrm{B} 6)$ mice did not show any deficit in sensing noxious heat when assayed by hot plate, tail flick and Hargreaves of radiation heat (Supplementary information, Fig. S5d-f). Furthermore, the KO (B6) mice showed normal responses in other behavioral tests, including Rotarod test for assaying overall mobility and Von Frey test for assaying mechanosensation (Supplementary information, Fig. S5g, h). Collectively, these data suggest that the keratinocytespecific STIM $1^{\mathrm{Ker} / \mathrm{Ker}}$ (KO) mice have specifically altered behaviors in preferring warm temperatures, which are unlikely due to developmental changes of the skin morphology (see also Supplementary information, Fig. S1e). 

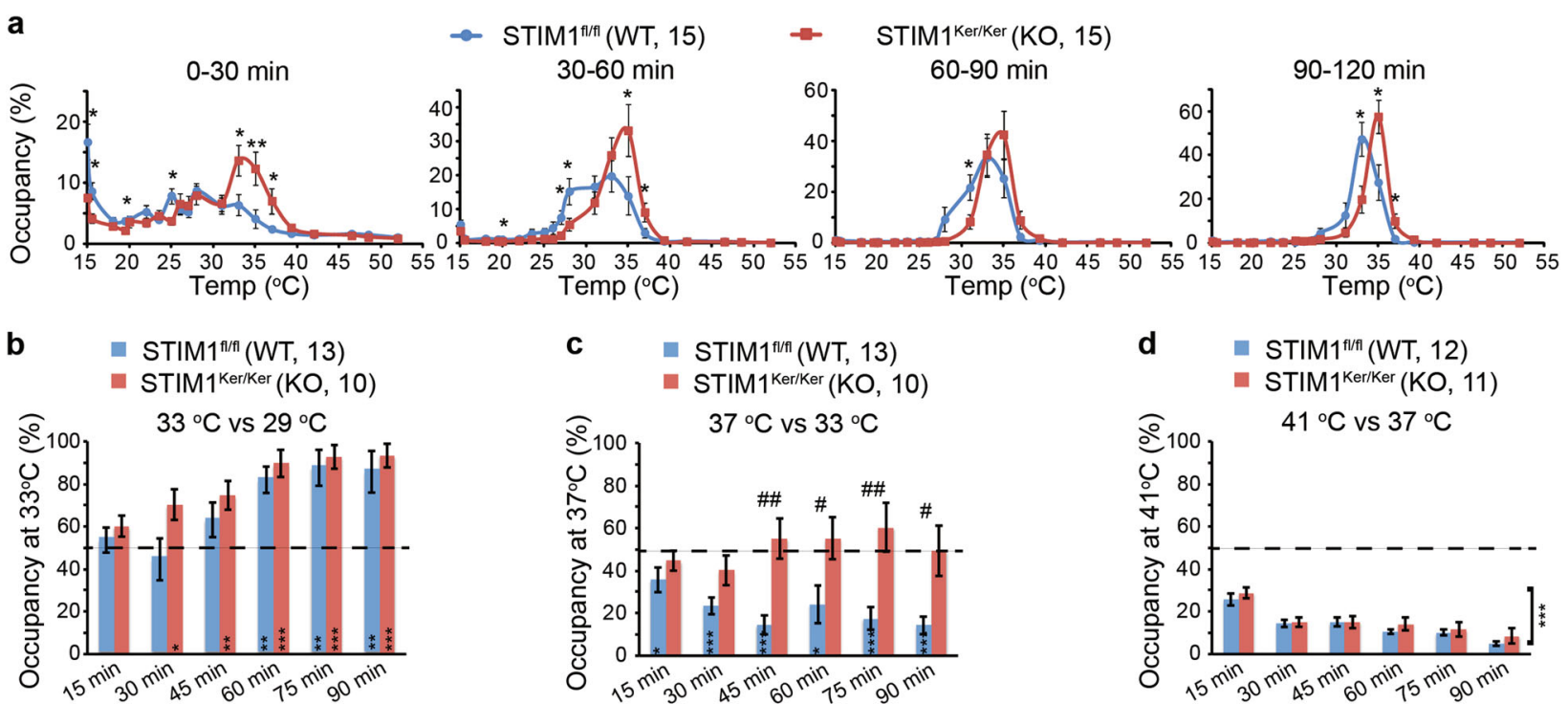
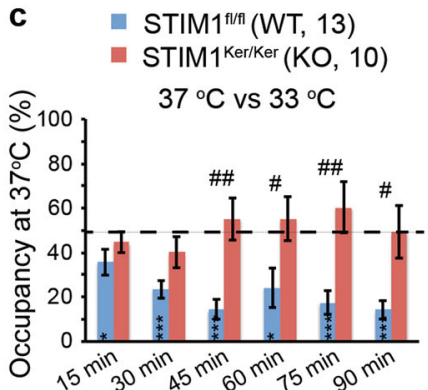
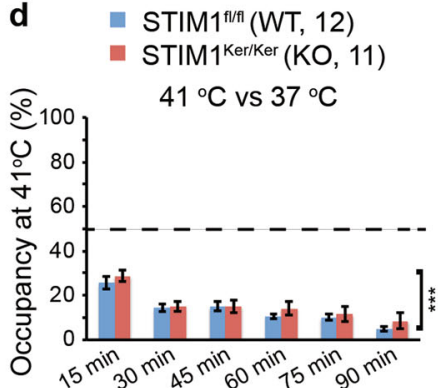
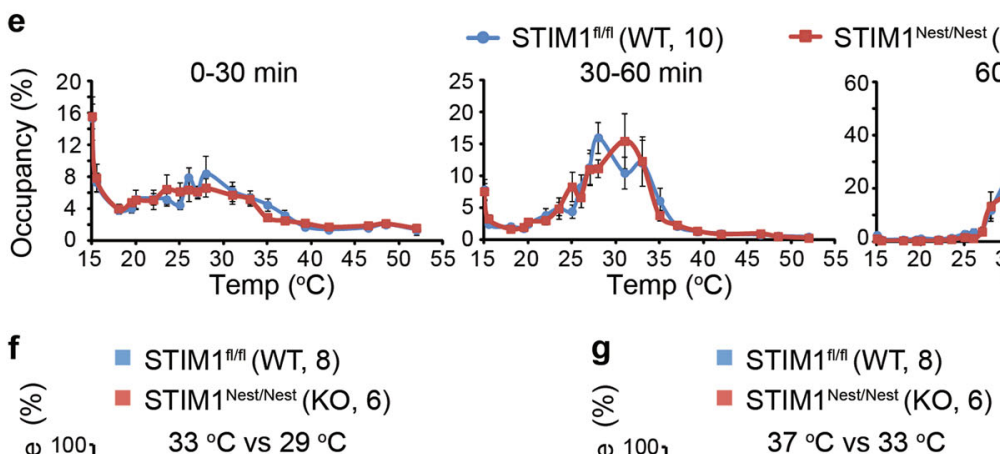

(KO, 12)
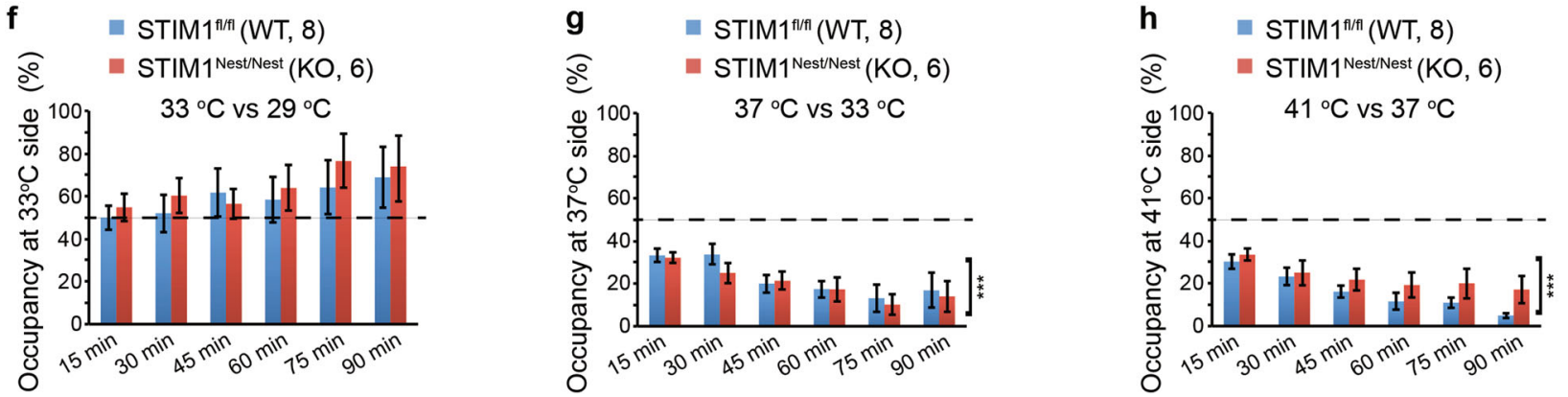

Fig. 4 Effect of keratinocyte-specific or neuron-specific knockout of STIM1 on thermotaxis and two-temperature choice behaviors. a, e Thermal gradient behaviors at the indicated time period of the male STIM $1^{\mathrm{f} / \mathrm{fl}}$ (WT) and STIM $1^{\text {Ker/Ker }}$ (KO) mice in the B6CBA mixed genetic background (a) or the male STIM1 $1^{\mathrm{fl} / \mathrm{fl}}$ (WT) and STIM1 ${ }^{\text {Nest/Nest }}$ (KO) mice in the C57BL/6 genetic background (e). Unpaired Student's $t$-test between the two genotypes, ${ }^{*} P<0.05$. b- $\mathbf{d}$ and $\mathbf{f}-\mathbf{h}$ Percentage of occupancy in the indicated temperature zones of the male STIM1 ${ }^{\mathrm{f} / \mathrm{fl}}$ (WT) and STIM $1^{\text {Ker/Ker }}(\mathrm{KO})$ mice (b-d) or the STIM $1^{\mathrm{f} / \mathrm{fl}}$ (WT) and STIM1 $1^{\text {Nest/Nest }}$ (KO) mice (f-h). "indicates unpaired Student's $t$-test between the two genotypes, ${ }^{\#} P<0.05$, ${ }^{\# \#} P<0.01$, \#\#\# $P<0.001$. *indicates paired Student's $t$-test of either genotypes for preference between the two tested temperatures under the indicated test paradigm, ${ }^{*} P<0.05,{ }^{* *} P<0.01,{ }^{* * *} P<0.001$

$\mathrm{STIM} 1^{\mathrm{Ker} / \mathrm{Ker}}(\mathrm{KO})$ mice utilize an OPT of $\sim 34^{\circ} \mathrm{C}$ as a reference temperature for warm preference

The thermotaxis gradient results suggest that the $\operatorname{STIM} 1^{\mathrm{fl} / \mathrm{fl}}(\mathrm{WT})$ and STIM1 $1^{\mathrm{Ker} / \mathrm{Ker}}(\mathrm{KO})$ mice have distinct OPTs, allowing us to examine the mechanism by which mice are capable of detecting subtle temperature variations from the thermoneutral skin temperature of $\sim 33^{\circ} \mathrm{C}$. Based on the temperature preference profile (Fig. 4a), we hypothesize that mice prefer temperatures closer to their OPTs, but do not distinguish temperatures that are equally but oppositely deviated from their OPTs within the warm temperature range. Basically, the OPT is utilized as a reference temperature (set point) for determining warm-sensing behaviors. We designed two-temperature choice assays to test this hypothesis.

When tested at $37^{\circ} \mathrm{C}$ vs $33^{\circ} \mathrm{C}$, the $\mathrm{KO}$ (B6) mice still tended to preferred $33^{\circ} \mathrm{C}$, but not significantly (Fig. 5a), prompting us to assume an OPT of $\sim 34^{\circ} \mathrm{C}$ for the $\mathrm{KO}(\mathrm{B} 6)$ mice. We therefore subjected the mice to the testing paradigms of $36^{\circ} \mathrm{C}$ vs $32{ }^{\circ} \mathrm{C}\left(2{ }^{\circ} \mathrm{C}\right.$ of temperature deviation from $34^{\circ} \mathrm{C}$ at both directions) and $38^{\circ} \mathrm{C}$ vs $30^{\circ} \mathrm{C}\left(4^{\circ} \mathrm{C}\right.$ of temperature deviation from $34^{\circ} \mathrm{C}$ at both directions). In both test paradigms, while WT (B6) preferred the lower temperatures, KO (B6) completely lost this preference by spending significantly more time at either the $36^{\circ} \mathrm{C}$ side or the $38^{\circ} \mathrm{C}$ side (Fig. $5 \mathrm{~b}, \mathrm{c}$ ). We further subjected the mice to a more challenging paradigm on the $2{ }^{\circ} \mathrm{C}$ of temperature preference assay, $35^{\circ} \mathrm{C}$ vs $33^{\circ} \mathrm{C}\left(1{ }^{\circ} \mathrm{C}\right.$ of temperature deviation from $34^{\circ} \mathrm{C}$ at both directions). Although the WT (B6) and $\mathrm{KO}$ (B6) mice did not show statistically significant difference in spending time at the $35^{\circ} \mathrm{C}$ side, WT (B6) demonstrated the ability to significantly prefer $33^{\circ} \mathrm{C}$ over $35^{\circ} \mathrm{C}$, whereas the $\mathrm{KO}$ (B6) mice completely lost preference for either temperature (Fig. $5 \mathrm{~d}$ ). 

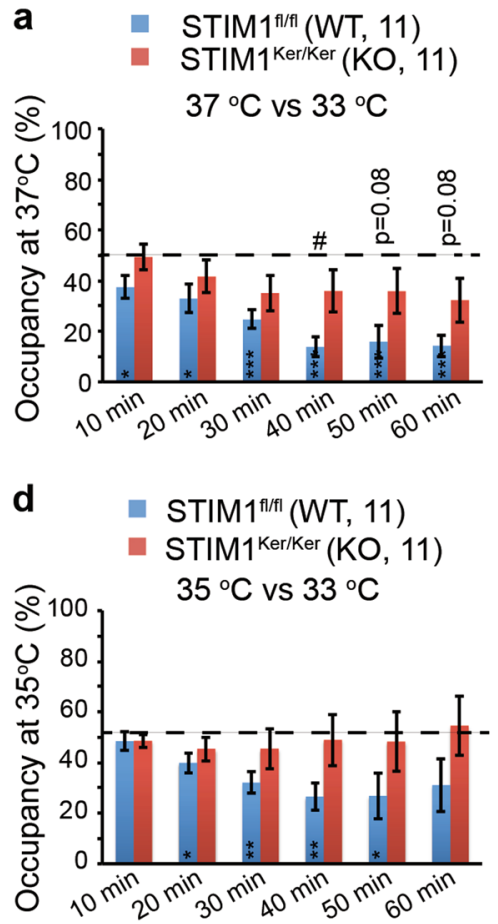

b

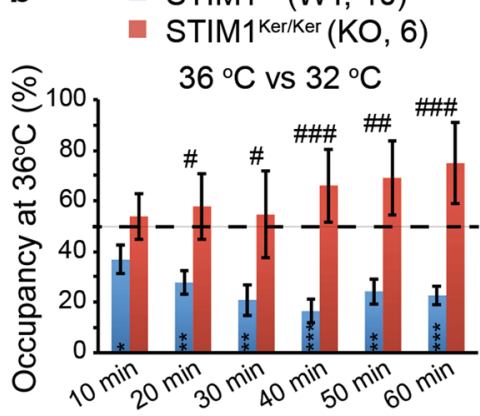

STIM1 ${ }^{\mathrm{flfl}}(\mathrm{WT}, 10)$

- STIM1 Ker/Ker $(K O, 6)$

e
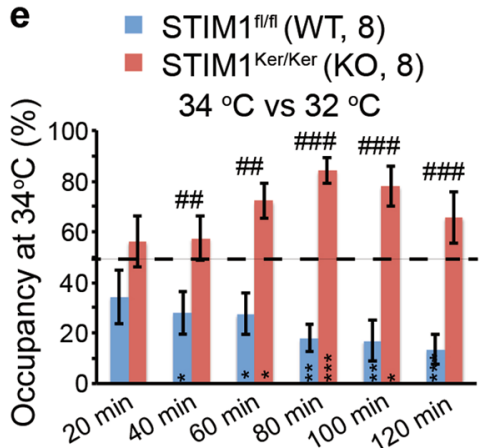

C

- STIM1 $1^{\text {fl/fII }}(\mathrm{WT}, 7)$

- STIM1Kerker $(K O, 9)$

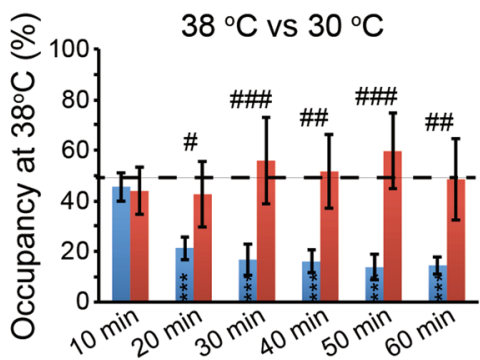

f
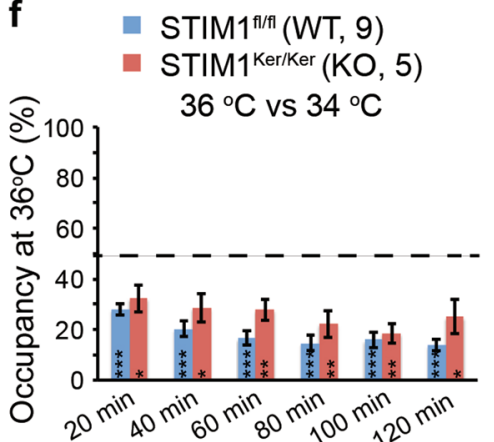

Fig. 5 Two-temperature choice behaviors of the $\mathrm{STIM} 1^{\mathrm{fl} / \mathrm{fl}}(\mathrm{WT})$ or $\mathrm{STIM} 1^{\mathrm{Ker} / \mathrm{Ker}}$ (KO) littermate mice in the $\mathrm{C} 57 \mathrm{BL} / 6 \mathrm{genetic}$ background. Percentage of occupancy in the indicated temperature zones of the male STIM1 $1^{\mathrm{fl} / \mathrm{fl}}$ (WT) and STIM $1^{\mathrm{Ker} / \mathrm{Ker}}$ (KO) mice in the C57BL/6 genetic background. \#indicates unpaired Student's $t$-test between the two genotypes, ${ }^{\#} P<0.05,{ }^{\# \#} P<0.01,{ }^{\# \# \#} P<0.001$. ${ }^{*}$ indicates paired Student's $t$ test of either genotypes for preference between the two tested temperatures under the indicated test paradigm, ${ }^{*} P<0.05,{ }^{* *} P<0.01,{ }^{* * *} P<$ 0.001

WT mice might have an OPT of $\sim 32^{\circ} \mathrm{C}$ (Fig. 4 a and see also below Fig. $6 \mathrm{~h}, \mathrm{i})$. We therefore subjected the mice to a test paradigm of $34^{\circ} \mathrm{C}$ vs $32{ }^{\circ} \mathrm{C}$, the respective OPTs for $\mathrm{KO}(\mathrm{B} 6)$ and WT (B6). Remarkably, $\mathrm{WT}(\mathrm{B} 6)$ and $\mathrm{KO}(\mathrm{B} 6)$ mice showed completely opposite preference behaviors: $\mathrm{WT}(\mathrm{B} 6)$ preferred $32^{\circ} \mathrm{C}$ over $34^{\circ} \mathrm{C}$, whereas $\mathrm{KO}$ (B6) preferred $34^{\circ} \mathrm{C}$ over $32^{\circ} \mathrm{C}$ (Fig. 5e). $\mathrm{KO}(\mathrm{B} 6)$ spent significantly more time at the $34^{\circ} \mathrm{C}$ side than WT(B6) did (Fig. 5e). To the best of our knowledge, STIM1 represents the first reported thermosensor whose ablation leads to a flipped temperature sensing behavior. Consistent with our prediction that mice prefer temperatures closer to their OPTs, when tested at $36^{\circ} \mathrm{C}$ vs $34^{\circ} \mathrm{C}$, both $\mathrm{WT}(\mathrm{B} 6)$ and $\mathrm{KO}(\mathrm{B} 6)$ preferred $34^{\circ} \mathrm{C}$ over $36^{\circ} \mathrm{C}$ (Fig. 5f). These data support the hypothesis that $\mathrm{KO}(\mathrm{B} 6)$ mice utilized $34^{\circ} \mathrm{C}$ as a reference temperature to explore temperature derivation from this set-point temperature. WT mice always preferred the temperature side that is closer to their OPT of $32^{\circ} \mathrm{C}$ in the tested paradigms (Fig. 5).

Collectively, these data suggest that mice utilize the STIM1defined OPT as a reference temperature for precise warm sensation. We refer this warm-sensing mechanism as a reference temperature mechanism.

STIM1- $\Delta \mathrm{K}$ knock-in mice have altered OPT and warm preference behaviors

To address whether the role of STIM1 in defining the OPT and warm-sensing behaviors depends on its thermosensitivity, we next examined whether the STIM1- $\Delta \mathrm{K}$ mice may recapitulate the phenotypes of STIM $1^{\mathrm{Ker} / \mathrm{Ker}}(\mathrm{KO})$ mice in warm sensation. Under the test paradigms of $33^{\circ} \mathrm{C}$ vs $29^{\circ} \mathrm{C}, 37^{\circ} \mathrm{C}$ vs $33^{\circ} \mathrm{C}$ and $41^{\circ} \mathrm{C}$ vs $37^{\circ} \mathrm{C}$ (Fig. $6 \mathrm{a}-\mathrm{C}$ ), STIM1- $\Delta \mathrm{K}$ male mice specifically lost the preference for $33^{\circ} \mathrm{C}$ over $37^{\circ} \mathrm{C}$ by spending significantly more time at the $37^{\circ} \mathrm{C}$ side (Fig. $6 \mathrm{~b})$, reminiscent of the $\mathrm{STIM} 1^{\mathrm{Ker} / \mathrm{Ker}}(\mathrm{KO})$ mice in the mixed genetic background (Fig. $4 \mathrm{~b}-\mathrm{d}$ ). According to the proposed reference temperature hypothesis, we reasoned that STIM1- $\Delta \mathrm{K}$ mice might have an OPT of $\sim 35^{\circ} \mathrm{C}$ so that they can indistinguishably gravitate between $33^{\circ} \mathrm{C}$ and $37^{\circ} \mathrm{C}\left(2^{\circ} \mathrm{C}\right.$ of deviation from the assumed reference temperature in both directions). In line with this, when given $1^{\circ} \mathrm{C}$ or $4^{\circ} \mathrm{C}$ of deviation from the reference temperature of $35^{\circ} \mathrm{C}$ at both sides: $36^{\circ} \mathrm{C}$ vs $34^{\circ} \mathrm{C}$ and $39{ }^{\circ} \mathrm{C}$ vs $31^{\circ} \mathrm{C}$, respectively, WT mice robustly preferred the lower temperature side (Fig. $6 \mathrm{~d}$, e). In contrast, STIM1- $\Delta \mathrm{K}$ mice did not robustly distinguish these temperature pairs by spending significantly more time at the warmer temperature side (Fig. 6d, e). Furthermore, under a test paradigm of $35^{\circ} \mathrm{C}$ vs $33^{\circ} \mathrm{C}$, compared to WT, STIM1- $\Delta \mathrm{K}$ mice showed a reversed preference of $35^{\circ} \mathrm{C}$ over $33^{\circ} \mathrm{C}$ by spending significantly more time at the $35^{\circ} \mathrm{C}$ side (Fig. $6 \mathrm{f}$ ). It is worth noting that similar behavioral responses have been consistently observed in all three independent batches of tested mice with ages ranging from 6-9 weeks and 12-16 weeks (Supplementary information, Fig. S6a). Both groups of mice preferred $35^{\circ} \mathrm{C}$ over $37^{\circ} \mathrm{C}$, consistent with the idea that mice prefer temperatures closer to the reference temperature (Fig. $6 \mathrm{~g}$ ).

We designed additional temperature paradigms to identify the reference temperature for the WT littermates. Under a test paradigm of $34^{\circ} \mathrm{C}$ vs $32{ }^{\circ} \mathrm{C}$, WT mice preferred $32{ }^{\circ} \mathrm{C}$ over $34^{\circ} \mathrm{C}$ (Fig. 6h). However, they were unable to choose between $34^{\circ} \mathrm{C}$ and $30^{\circ} \mathrm{C}$ (Fig. 6i), suggesting that WT mice have an OPT of $\sim 32^{\circ} \mathrm{C}$, consistent with that estimated by the temperature gradient assay (Fig. 4a). In both test paradigms, the STIM1- $\Delta \mathrm{K}$ mice behaved differently from the WT mice by spending significantly more time at the $34^{\circ} \mathrm{C}$ side, consistent with the observation that they preferred the side closer to their OPT of $\sim 35^{\circ} \mathrm{C}$ (Fig. $6 \mathrm{~h}, \mathrm{i}$ ).

Similar to STIM1 ${ }^{\mathrm{Ker} / \mathrm{Ker}}(\mathrm{KO})$ mice, STIM1- $\Delta \mathrm{K}$ mice did not show other somatosensory deficits (Supplementary information, Fig. S6b-e), precluding morphological changes of the skin. Taking all these behavioral analyses together, we propose that the STIM1 thermosensitivity in keratinocytes plays a critical role in determining the OPT for precise warm sensation. 

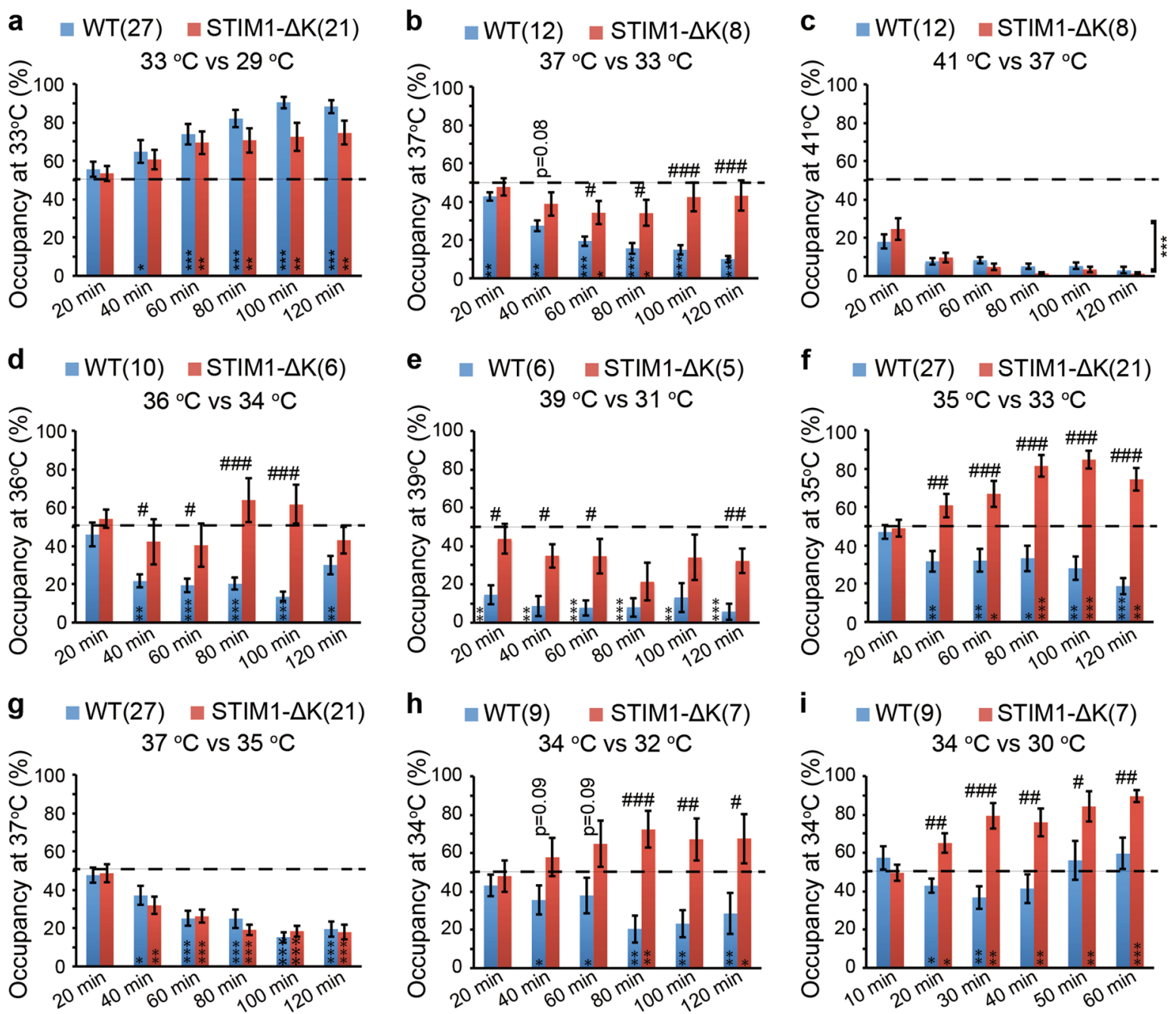

Fig. 6 Two-temperature choice behaviors of WT and STIM1- $\Delta \mathrm{K}$ littermate mice in the C57BL/6 genetic background. Percentage of occupancy in the indicated temperature zones of the male WT and littermate STIM1- $\Delta \mathrm{K}$ mice in the C57BL/6 genetic background. \#indicates unpaired

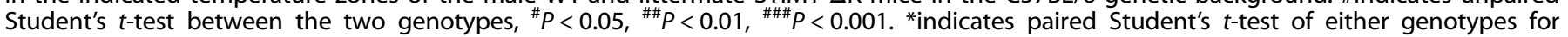
preference between the two tested temperatures under the indicated test paradigm, ${ }^{*} P<0.05,{ }^{* *} P<0.01,{ }^{* *} P<0.001$

Keratinocyte-specific deletion of STIM1 decreases the in vivo responsiveness of DRG neurons to warm temperatures Selective keratinocyte stimulation via chemogenetics or optogenetics has been shown to modulate firing of primary sensory neurons including heat-sensitive fibers and trigger nociceptive behaviors, demonstrating that keratinocytes can affect the activities of skin-innervating sensory neurons. ${ }^{50,51}$ We therefore asked whether keratinocyte-expressing STIM1 affects the in vivo responsiveness of DRG neurons to temperature stimulation. We crossed the STIM $1^{\text {Ker/Ker }}($ KO) mice with the Pirt-GCAMP3 mice that express the genetically encoded $\mathrm{Ca}^{2+}$ indicator GCAMP3 specifically in primary sensory neurons, and carried out in vivo $\mathrm{Ca}^{2+}$ imaging of the whole lumbar 4 (L4) DRG neurons of the STIM $1^{\mathrm{fl} / \mathrm{fl}}(\mathrm{WT}) /$ Pirt-GCAMP3 and STIM $1^{\text {Ker/Ker }}(\mathrm{KO}) /$ Pirt-GCAMP3 littermate mice upon a series of temperature stimulations from $25^{\circ} \mathrm{C}$ to $30^{\circ} \mathrm{C}, 33^{\circ} \mathrm{C}, 37^{\circ} \mathrm{C}, 41^{\circ} \mathrm{C}$ and $50^{\circ} \mathrm{C}$ (Fig. 7a). STIM $1^{\mathrm{fl} / \mathrm{fl}}(\mathrm{WT}) /$ Pirt-GCAMP3 showed a small number of warm-responding neurons (Fig. 7a). However, upon a stimulation of a noxious heat of $50^{\circ} \mathrm{C}$, the responding neurons and the intracellular $\mathrm{Ca}^{2+}$ amplitude were drastically increased (Fig. 7a and Supplementary information, Fig. S7a). These results are consistent with previous reports of low activities of sensory neurons in response to warm temperatures within the temperature range of $30^{\circ} \mathrm{C}-42^{\circ} \mathrm{C} ., 27,52$ Importantly, STIM1 ${ }^{\mathrm{Ker} / \mathrm{Ker}}(\mathrm{KO}) / \mathrm{Pirt}-G C A M P 3$ mice showed significantly reduced warm-responding neurons, whereas the noxious heat-responding neurons remained unchanged (Fig. 7a). These data suggest that temperature-induced STIM1 activities in keratinocytes can specifically modulate the responsiveness of DRG neurons to warm temperatures, consistent with the behavioral results (Figs. 4, 5 and Supplementary information, Fig. S4).

TRPA1 is likely to function as a downstream transduction channel in DRG neurons for warm sensation

A previous study has proposed that tryptase, an endogenous activator of the GPCR protease activated receptor 2 (PAR2), activates STIM1-mediated SOCE in keratinocytes, resulting in the expression and release of thymic stromal lymphopoietin (TSLP), which evokes itch sensation via employing TRPA1 as the downstream transduction channel. ${ }^{32}$ TRPA 1 is expressed in a subset of TRPV1-positive DRG neurons (but not in keratinocytes ${ }^{53}$ ) and functions as a promiscuous transduction channel for a wide variety of reactive or non-reactive substances involved in pain and itch. $^{32,54,55}$ Consistent with the previous report, ${ }^{32}$ we found that TRPA $1^{-1}$ mice indeed showed defective tryptase-evoked itch responses (Supplementary information, Fig. S7b). However, the role of keratinocyte-specific STIM1 in mediating tryptase-evoked itch has not been directly tested in the previous study. ${ }^{32}$ We found that keratinocyte-specific STIM $1^{\mathrm{Ker} / \mathrm{Ker}}(\mathrm{KO})$ mice showed reduced 
a

STIM1 1//fi(WT)/Pirt-GCAMP3 (7)

- STIM1 Ker/Ker (KO)/Pirt-GCAMP3 (8)

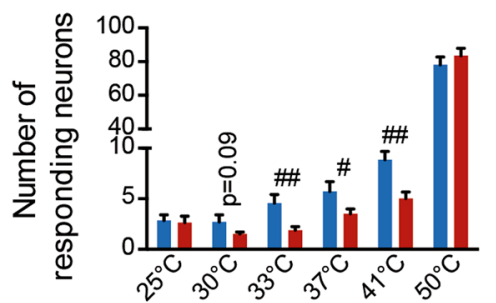

C

- TRPA $1^{+/+} /$Pirt-GCAMP3 (11)

- TRPA1 ${ }^{-1-/ P i r t-G C A M P 3 ~(12) ~}$

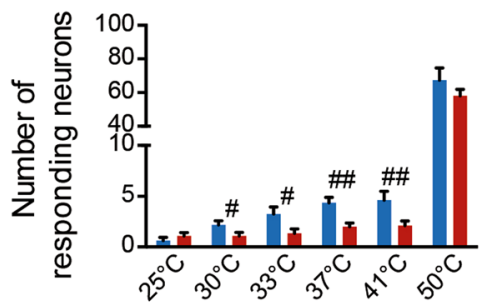

e STIM1

thermosensitivity DRG activation

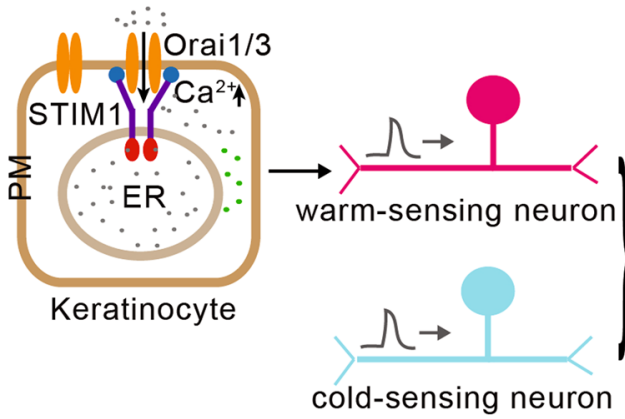

b

STIM1 ${ }^{\text {fl/fII }}(\mathrm{WT})$
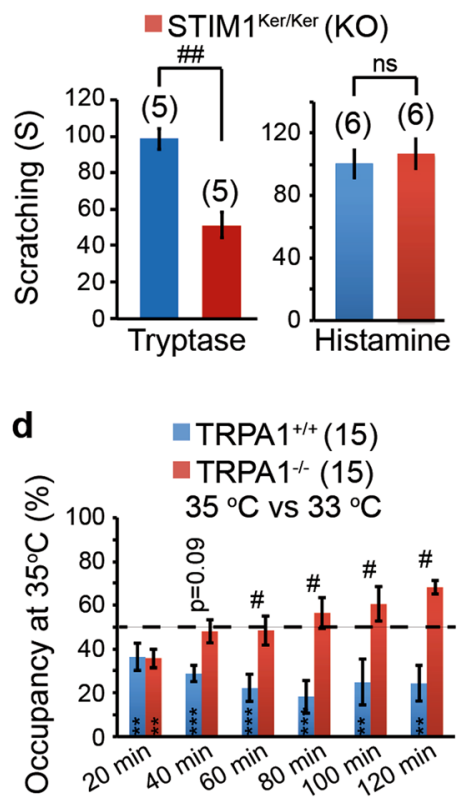

Optimal preference temperature determination

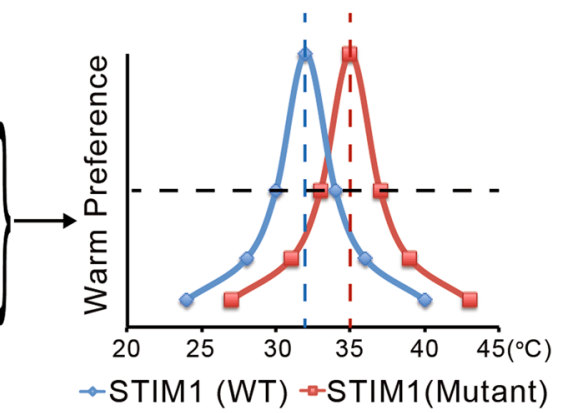

Fig. 7 In vivo DRG Ca ${ }^{2+}$ imaging and behavioral analysis. a, $\mathbf{c}$ In vivo $\mathrm{Ca}^{2+}$ imaging of the lumber 4 DRG neurons of the STIM1 ${ }^{\mathrm{fl} / \mathrm{fl}}$ (WT) and STIM $1^{\mathrm{Ker} / \mathrm{Ker}}(\mathrm{KO})$ mice (a) or the TRPA $1^{+/+}$and TRPA $1^{-/-}$littermate mice (c) showing the number of responding neurons to the indicated temperature changes. The mice expressed the genetically encoded $\mathrm{Ca}^{2+}$ indicator GCAMP3 for in vivo Ca ${ }^{2+}$ imaging. Unpaired Student's $t-$ test, ${ }^{\#} P<0.05,{ }^{\#} P<0.01$. b Tryptase (left panel) or histamine (right panel) induced itch responses of littermate male STIM $1^{\mathrm{f} / \mathrm{fl}}$ (WT) and $\mathrm{STIM} 1^{\mathrm{Ker} / \mathrm{Ker}}$ (KO) mice. Unpaired Student's $t$-test, ${ }^{\# \#} P<0.01$. d Percentage of occupancy at the $35^{\circ} \mathrm{C}$ side of the TRPA $1^{+/+}$and $T R P A 1^{-/}$ littermate mice under a test paradigm of $35^{\circ} \mathrm{C}$ vs $33^{\circ} \mathrm{C}$. \#indicates unpaired Student's $t$-test between the two genotypes, ${ }^{\#} P<0.05 .{ }^{*}$ indicates paired Student's $t$-test of either genotypes for preference between the two tested temperatures, ${ }^{* *} P<0.01,{ }^{* * *} P<0.001$. e Schematic diagram showing STIM1 thermosensitivity-mediated determination of the optimal preference temperature (OPT). In keratinocytes, the ER-residing STIM1 can mediate temperature-induced $\mathrm{Ca}^{2+}$ influx via coupling to Orai1 and Orai3 ion channels located on plasma membrane (PM; left panel). The red and blue parts of the STIM1 molecule, respectively, represent its luminal $\mathrm{Ca}^{2+}$ sensor domain and cytosolic C-terminal Kdomain that is critical for its temperature sensitivity. The grey dots represent $\mathrm{Ca}^{2+}$ ion. STIM-mediated temperature responses of keratinocytes might affect the in vivo warm responsiveness of DRG neurons (middle panel). The right panel illustrates that mice utilize the STIM1-defined OPT as a reference temperature for effective warm preference. The solid colored lines represent the putative warm preference profiles of the STIM1(WT) and STIM1 (mutant) mice, while the dashed colored lines indicate their respective OPTs, which might reflect the homeostatic temperature point at which the net aversive force from the warm-responding neurons and the counteracting cold-sensing neurons is minimal. The dark dashed line illustrates that mice do not distinguish two warm temperatures that are equally deviated from the OPT in opposite directions (i.e., WT: $30^{\circ} \mathrm{C}$ vs $34^{\circ} \mathrm{C} ; \mathrm{STIM} 1-\Delta \mathrm{K}: 33^{\circ} \mathrm{C}$ vs $37^{\circ} \mathrm{C}$ ). Thus, we propose that mice use the OPT as a reference temperature for effective warm sensation

tryptase-evoked itch responses, but normal histamine-induced itch that is originated from mast cells instead of keratinocytes (Fig. 7b). Together with the previous report, ${ }^{32}$ our data have established the STIM1-TRPA1 signal transduction pathway in keratinocyte-originated itch sensation.

Next, we tested whether TRPA1 might be involved in STIM1dependent modulation of the warm responsiveness of DRG neurons and the warm preference behaviors. Importantly, in vivo DRG $\mathrm{Ca}^{2+}$ imaging revealed that $T R P A 1^{-1-}$ mice had reduced warm-responding neurons, but retained normal noxious heatresponding neurons (Fig. 7c). Furthermore, the TRPA $1^{-/-}$mice were unable to distinguish between $33^{\circ} \mathrm{C}$ and $35^{\circ} \mathrm{C}$ (Fig. $7 \mathrm{~d}$ ), but behaved normally when tested at $33^{\circ} \mathrm{C}$ vs $29^{\circ} \mathrm{C}$ or $41^{\circ} \mathrm{C}$ vs $37^{\circ} \mathrm{C}$ (Supplementary information, Fig. S7c).

We asked whether TSLP might serve as the transduction molecule for STIM1-dependent temperature sensation, and therefore measured the release of TSLP from keratinocytes cultured at $33^{\circ} \mathrm{C}, \quad 35^{\circ} \mathrm{C}$ and $37^{\circ} \mathrm{C}$. STIM $1^{\mathrm{Ker} / \mathrm{Ker}}(\mathrm{KO})$ keratinocytes had a 
modestly decreased level of TSLP at $33^{\circ} \mathrm{C}$, but not at $35^{\circ} \mathrm{C}$ and $37^{\circ}$ C (Supplementary information, Fig. S7d, left panel). Furthermore, WT and STIM1- $\Delta \mathrm{K}$ keratinocytes had comparable TSLP levels (Supplementary information, Fig. S7d, right panel). These data suggest that TSLP might not be the major transduction molecule for the proposed STIM1-TRPA1 signaling pathway between keratinocytes and DRG neurons.

In addition to TSLP, keratinocytes have been reported to release other neuroactive substances such as ATP, prostaglandin E2 (PGE2), nitric oxide (NO) and endothelin-1. ${ }^{26,56-58}$ When measured under the treatment of warm temperatures (e.g., ATP and endothelin-1) or during and after heating to $45^{\circ} \mathrm{C}$ for inducing the stronger heat on- and off-response of $\mathrm{Ca}^{2+}$ influx (e.g., PGE2 and NO), these substances appeared not to depend on the expression of STIM1 in keratinocytes (Supplementary information, Fig. S7e-h). We further screened heat-induced release of 23 different cytokines from cultured keratinocytes using the Bioplex cytokine assay from Biorad and identified mouse keratinocytederived cytokine $(\mathrm{mKC})$ as a heat-dependent cytokine (Supplementary information, Fig. S7i). However, the heat-induced mKC release was not affected in the $\mathrm{STIM} 1^{\mathrm{Ker} / \mathrm{Ker}}(\mathrm{KO})$ keratinocytes (Supplementary information, Fig. S7i). Thus, despite these intensive efforts, the STIM1-dependent transduction molecules released from keratinocytes remain to be determined.

Given the established STIM1-TRPA1 signal transduction pathway in mediating keratinocyte-originated itch sensation, and that mouse TRPA 1 itself is not activated by heat but involved in in vivo warm responsiveness of DRG neurons and warm preference behaviors, it is reasonable to propose that TRPA1 might function as a downstream transduction channel for mediating keratinocyte STIM1-dependent warm sensation. Nevertheless, since the signaling module has not been identified, it remains possible that TRPA1 might function independently of the keratinocyte-expressing STIM1 for warm sensation.

\section{DISCUSSION}

In the present study, using tissue-specific STIM1 KO mice, we have shown that STIM1 mediates temperature-induced $\mathrm{Ca}^{2+}$ responses in keratinocytes (Fig. 1), affects in vivo warm responses of DRG neurons (Fig. 7a), and defines the OPT and warm preference behaviors (Figs. 4, 5). Importantly, via characterizing the thermally inactive STIM1- $\Delta \mathrm{K}$ knock-in mice, we have further demonstrated that STIM1-dependent temperature sensation specifically relies on its thermosensitivity instead of its otherwise well-characterized role in sensing $\mathrm{ER} \mathrm{Ca}^{2+}$ depletion (Figs. 2,6). To the best of our knowledge, this is the first report that specifically correlates the thermosensitivity of a putative temperature sensor to its in vivo role in temperature sensation. Thus, we believe that STIM1 functions as an in vivo warm sensor in the skin. However, given the unsuccessful identification of the signaling molecule for converting STIM1-dependent temperature responses in keratinocytes to sensory neurons, we currently cannot totally exclude the possibility that keratinocyte-expressing STIM1 might somehow modulate the actual thermal sensory mechanism. Nevertheless, such modulatory effect depends on the STIM1 thermosensitivity.

The identification of STIM1 as a novel thermosensor diversifies the previously established types of temperature sensors including thermoTRPs and the $\mathrm{Ca}^{2+}$-activated chloride channel Anoctamine 1 (ANO1, also known as TMEM16A). ${ }^{59}$ In contrast to other identified thermosensors being ion channels expressed on plasma membrane, STIM1 is an intracellularly localized ER membrane protein. Intriguingly, via coupling to different ion channels such as Orai 1 and Orai3 on plasma membrane, it can mediate various forms of temperature responses including heat on-, off-responses and basal $\mathrm{Ca}^{2+}$ influx in the warm temperature range, further diversifying its temperature response profile. Despite the robust STIM1-dependent acute heat on- and off-responses when heated to noxious temperatures (Fig. 1), the STIM $1^{\text {Ker/Ker }}(\mathrm{KO})$ mice did not show any deficit in sensing noxious heat (Supplementary information, Fig. S5d-e) and had normal heat-responding DRG neurons (Fig. 7a). Given that a combination of TRPV1, TRPM3 and TRPA 1 plays a dominant role in determining the acute sensation of noxious heat, ${ }^{17}$ our data suggest that STIM1 may play a minor or redundant role in sensing noxious heat in vivo. On the other hand, the STIM1 thermosensitivity-mediated basal $\mathrm{Ca}^{2+}$ response may account for STIM1-defined OPT and warm preference behaviors. STIM1 is activated by heat, whereas the functional coupling between STIM1 and Orai1 is inhibited by heat. ${ }^{28}$ Such a mechanism may lead to the STIM1-dependent bell-shaped basal $\mathrm{Ca}^{2+}$ influx peaking around $30^{\circ} \mathrm{C}-33^{\circ} \mathrm{C}$ (Fig. $2 \mathrm{~g}$ ), which remarkably mirrors the thermotaxis behaviors of mice in seeking warm temperatures (Fig. 4a). Intriguingly, instead of abolishing warm sensation, keratinocyte-specific deletion of STIM1 shifts the OPT of mice from $32{ }^{\circ} \mathrm{C}$ to $34^{\circ} \mathrm{C}$, resulting in striking behavioral changes in sensing $1{ }^{\circ} \mathrm{C}$ of temperature deviation from the thermoneutral skin temperature of $33^{\circ} \mathrm{C}$ (Fig. 5). For instance, while STIM1 $1^{\mathrm{fl} / \mathrm{fl}}(\mathrm{WT})$ mice preferred $32^{\circ} \mathrm{C}$ over $34^{\circ} \mathrm{C}, \mathrm{STIM} 1{ }^{\mathrm{Ker} / \mathrm{Ker}}(\mathrm{KO})$ mice reversely preferred $34^{\circ} \mathrm{C}$ over $32^{\circ} \mathrm{C}$ (Fig. 5e). STIM $1^{\text {Ker/Ker }}$ (KO) mice remained sensitive to warm temperatures (Figs. 4,5 ) and still had warmresponding DRG neurons (Fig. 7a), indicating the involvement of other warm sensors. Notably, all the characterized knockout mice of other putative warm sensors only show partial deficits in sensing warm temperatures as well. For instance, the TRPM2 KO mice only show deficit in the test paradigm of $33^{\circ} \mathrm{C}$ vs $38^{\circ} \mathrm{C}$, but not that of $28^{\circ} \mathrm{C}$ vs $33^{\circ} \mathrm{C}$ or $33^{\circ} \mathrm{C}$ vs $43^{\circ} \mathrm{C}$. . Given the precedent demonstration that multiple thermally activated TRP channels are collaboratively required for noxious heat sensation, ${ }^{17}$ we speculate that STIM1 might cooperate with other warm sensors to control the full spectrum of warm sensation in vivo.

Keratinocytes have been postulated to contribute to warm sensation as they can effectively sense subtle temperature changes occurring at the skin surface and express TRPV3 and TRPV4, which have their temperature activation thresholds near the thermoneutral skin temperature. ${ }^{22,23}$ However, the lack of strong behavioral deficits in the TRPV3 and TRPV4 double knockout mice in sensing warm temperatures has made this hypothesis ambiguous. ${ }^{24}$ In the present study, we have obtained the following key evidence to support the direct contribution of keratinocytes to warm sensation. First, STIM1 thermosensitivity mediated temperature-induced $\mathrm{Ca}^{2+}$ influx in keratinocytes

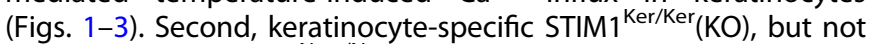
neuron-specific STIM1 ${ }^{\text {Nest/Nest }}(\mathrm{KO})$ mice displayed altered behaviors in warm temperature preferences (Figs. 4 and 5). Third, $\mathrm{STIM} 1^{\mathrm{Ker} / \mathrm{Ker}}(\mathrm{KO})$ mice had reduced in vivo warm-responding DRG neurons (Fig. 7a). Lastly, STIM1 ${ }^{\mathrm{Ker} / \mathrm{Ker}}(\mathrm{KO})$ mice showed specific defects in keratinocyte-originated itch responses as well (Fig. 7b). However, since the K14-Cre mice are expected to express Cre in skin Merkel cells as well, we could not totally exclude the potential contribution of Merkel cells or other skin cell types to warm sensation based on our characterization of the STIM1 ${ }^{\mathrm{Ker} / \mathrm{Ker}}(\mathrm{KO})$ mice.

Our data suggest that TRPA1 is likely to function as a downstream transduction channel for mediating keratinocyte STIM1-depenent warm sensation (Fig. 7b-d). However, the unsuccessful identification of the signaling molecule that transduces STIM1-dependent temperature responses of keratinocytes to sensory neurons raises the possibility that TRPA1 might function independently of keratinocyte-expressing STIM1 for warm sensation. Intriguingly, like TRPA1, DRG-expressing TRPM2, TRPV1 and P2X3 have all been implicated in warm sensation. $7,27,60,61$ However, their temperature activation properties appear to suggest that these ion channels do not function as direct warm sensors. For instance, P2X3 has not been reported to be thermally active, ${ }^{60}$ TRPA 1 is activated by cold $\left(<17^{\circ} \mathrm{C}\right),{ }^{10}$ TRPV1 is activated by noxious heat above $43^{\circ} \mathrm{C}_{1}^{4}$ and TRPM2 
endogenously expressed in neurons was reported to be activated by a temperature stimulus of $42{ }^{\circ} \mathrm{C}$ only in the presence of $\mathrm{H}_{2} \mathrm{O}_{2}{ }^{7}$ $A$ recent study has even questioned whether TRPM2 indeed mediates temperature responses in DRG neurons. ${ }^{17}$ Thus, it remains possible that these DRG-expressing ion channels might function as downstream transduction channels for mediating keratinocyte-originated warm sensation. Our finding that TRPA $1^{-1-}$ mice had altered preference between $33^{\circ} \mathrm{C}$ and $35^{\circ} \mathrm{C}$ and reduced warm-responding neurons supports this hypothesis (Fig. 7c, d). Interestingly, the convergence of the STIM1-TRPA1 signal transduction pathway for keratinocyte-originated warm and itch sensation might explain why warm temperature is a clinically relevant factor for subjects with atopic dermatitis. ${ }^{62}$

Our studies also provide important insights into the logic by which mammals achieve the striking capability to sense subtle temperature deviation from its thermoneutral skin temperature of $\sim 33^{\circ} \mathrm{C}$. By systematically analyzing various two-temperature choice paradigms within the warm temperature zone of $29{ }^{\circ} \mathrm{C}-41{ }^{\circ} \mathrm{C}$, we have obtained three key observations. First, mice have an OPT (optimal preference temperature), which we term reference temperature. Second, mice effectively prefer temperatures closer to the reference temperature. Third, mice are compromised to effectively distinguish two temperatures that are equally deviated from the reference temperature in opposite directions. Based on these data, we propose that mice may employ a peripheral reference temperature mechanism for effective warm sensation (Fig. 7e). Our observation that STIM1 expressed in keratinocytes can tune this reference temperature set point provides strong genetic evidence to support this hypothesis (Fig. 7e). Such a mechanism not only allows animals to precisely detect subtle temperature variations, but also renders them to habitat in a wide range of warm temperatures (i.e., $30^{\circ} \mathrm{C}$ and $38^{\circ} \mathrm{C}$ are indistinguishable for STIM $1^{\mathrm{Ker} / \mathrm{Ker}} \mathrm{KO}$ mice) (Fig. $5 \mathrm{C}$ ). Female mice might have a higher OPT than male mice so that females prefer warmer temperatures as shown in Fig. 5a and Supplementary information, Fig. S5a-c. Importantly, this mechanism allows us to predict the distinct warm preference behaviors of WT, STIM1 ${ }^{\mathrm{Ker} /}$ ${ }^{\mathrm{Ker}}(\mathrm{KO})$ and STIM1- $\Delta \mathrm{K}$ mice based on their respective reference temperatures of $\sim 32{ }^{\circ} \mathrm{C}, \sim 34^{\circ} \mathrm{C}$ and $\sim 35^{\circ} \mathrm{C}$. For instance, STIM $1^{\mathrm{fl} /}$ ${ }^{\mathrm{fl}}(\mathrm{WT})$ and STIM1 $1^{\mathrm{Ker} / \mathrm{Ker}}(\mathrm{KO})$ mice showed completely opposite preference behaviors in the $34^{\circ} \mathrm{C}$ vs $32^{\circ} \mathrm{C}$ test paradigm (Fig. 5e), while WT and STIM1- $\Delta \mathrm{K}$ mice had opposite preference between $35^{\circ} \mathrm{C}$ and $33^{\circ} \mathrm{C}$ (Fig. 6f). It would be interesting to apply this mechanism to guide the design of two-temperature preference paradigms to unveil altered warm-sensing behaviors of mice deficient in other putative warm sensors.

Previous studies have suggested that warm sensation could be collectively determined by the net aversive force derived from TRPM8-positive cold-sensing and the counteracting TRPV1positive heat-sensing neurons. ${ }^{11}$ Thus, the reference temperature might reflect the homeostatic temperature point at which the net aversive force from the two populations of neurons is minimal. We have shown that the keratinocyte-expressing STIM1 can affect the in vivo responses of DRG neurons to warm temperatures (Fig. 7a). Abolishing the STIM1 temperature sensitivity in STIM1 ${ }^{\text {ker/ker }}$ (KO) mice could lead to a decreased basal $\mathrm{Ca}^{2+}$ influx into keratinocytes (Fig. 2g) and a reduced responsiveness of heat-sensing neurons (Fig. 7a); consequently, a higher temperature might be required to achieve the aversive force from the heat-sensing neurons to counteract the opposite aversive force from the coldsensing neurons. This could result in a rightward shift of the OPT from $32{ }^{\circ} \mathrm{C}$ to $34^{\circ} \mathrm{C}$ and a behavioral preference of $34^{\circ} \mathrm{C}$ over $32{ }^{\circ} \mathrm{C}$ of the STIM $1{ }^{\text {ker/ker }}(\mathrm{KO})$ mice (Fig. $5 \mathrm{e}$ ). The presumable less aversive force from the heat-sensing neurons in the STIM $1^{\text {Ker/Ker }}(\mathrm{KO})$ mice might also explain why the mutant mice selected warmer temperatures faster than WT mice (Fig. 4a). The requirement of both cold- and heat-sensing neurons in determining warm sensation predicts that loss of warm sensors such as STIM1 and warm-sensing neurons alone will not produce a complete loss of warm sensation, consistent with our data that STIM1 mutant mice are still able to sense warm temperatures. Intriguingly, the STIM1defined reference temperature mechanism for peripheral warm sensation is reminiscent of that for core body temperature regulation in hypothalamus, ${ }^{63}$ raising the possibility that peripheral warm sensation and central core temperature regulation may share similar working principles to ensure temperature homeostasis.

\section{MATERIALS AND METHODS}

Culture of primary keratinocytes

Primary mouse keratinocytes from newborn mice (P0-P2) was cultured according to the previous protocol. ${ }^{26,40}$ Briefly, newborn mice were decapitated. After being soaked into $10 \%$ povidone, $70 \%$ ethanol and DPBS for 5 min, respectively, the back skin was removed, stripped of fat and floated (epidermis upward) in $0.25 \%$ trypsin for $1 \mathrm{~h}$ at $37^{\circ} \mathrm{C}$. Epidermal layer of the skin was peeled off, cut into smaller pieces in Cnt-02 medium (CELLnTEC, supplemented with $10 \% \mathrm{FBS}$ and $1 \times \mathrm{P} / \mathrm{S}$ ), and then stirred for $30 \mathrm{~min}$ at room temperature in a $100 \mathrm{~mL}$ bottle to get single cells. The cells were filtered $(70 \mu \mathrm{m}$ cell strainer), spun down $(1,000 \mathrm{rpm}, 3 \mathrm{~min})$, resuspended in CnT-02 medium (no extra serum, no extra $\mathrm{P} / \mathrm{S}$ ), plated on fibronectin and collagen IV $(10 \mu \mathrm{g} / \mathrm{mL})$-coated coverslips, and cultured for $2-3$ days at $37^{\circ} \mathrm{C}$ with $5 \% \mathrm{CO}_{2}$. For culture of keratinocytes from adult mice (6-8 weeks), the mice were sacrificed and the hair of the dorsal skin was removed with the electric shaver. The hairless back skin was removed and treated similarly to that for newborn mice except that the skin was treated with $1 \%$ trypsin for $2 \mathrm{~h}$ at $37^{\circ} \mathrm{C}$. The quality and purify of the cultured keratinocytes were illustrated in Supplementary information, Fig. S1a, b.

FLIPR and Fura-2 single-cell $\mathrm{Ca}^{2+}$ imaging

Temperature-induced $\mathrm{Ca}^{2+}$ responses were measured by FLIPR (Molecular Devices) using the single-wavelength $\mathrm{Ca}^{2+}$ indicator, Fluo-3, or single-cell $\mathrm{Ca}^{2+}$ imaging using the ratiometric $\mathrm{Ca}^{2+}$ indicator, Fura-2. The temperature change of the medium inside the well was controlled by a custom-designed temperature control device as described previously. ${ }^{64}$ The detailed protocols are described in Supplementary information, Data S1.

\section{Animals}

All experimental procedures were conducted in accordance with IACUC guidelines provided by The Scripps Research Institute, The Genomics Institute of Novartis Foundation, Tsinghua University and the Johns Hopkins University. The mouse lines used in this study include the constitutive STIM1 KO mice in C57BL/6 (STIM1 ${ }^{-1-}$, see Supplementary information, Data S1), STIM1 ${ }^{\mathrm{f} / \mathrm{fl}}$ mice in C57BL/' 6 (a generous gift from Dr. Anjana Rao), ${ }^{43}$ STIM1- $\Delta \mathrm{K}$ knock-in mice in C57BL/6 (see Supplementary information, Data S1), K14-Cre mice in B6CBA mixed genetic background (JAX, stock\# 004782) or backcrossed to C57BL/6 background for ten generations, NestinCre mice in C57BL/6 (JAX, stock\# 003771), TRPA1-deficient mice in B6;129 mixed genetic background (JAX, stock\# 6401) and the PirtGCAMP3 mice. 65

\section{Behavioral assays}

All experiments involving animals were conducted on littermate male mice at 6-16 weeks old except for Supplementary information, Fig. S5a-c where female littermates were used. No more than 5 mice were housed in a cage and raised in a light-dark cycle. Animals were randomly chosen for experimental subjects and acclimated for $\sim 1 \mathrm{~h}$ in the testing environment prior to experiments unless otherwise stated. For those mice that were not subject to nociceptive behaviors, they were repeatedly tested after having at least one day of rest. All experimental procedures 
were performed in a blinded manner. Some key behavioral experiments were verified by different experimenters. See Supplementary information, Data S1 for the detailed protocols for the temperature gradient, two-temperature choice and other behavioral assays.

The whole L4 DRG exposure surgery and in vivo L4 DRG $\mathrm{Ca}^{2+}$ imaging

Adult mice were anesthetized by i.p. injection of chloral hydrate $(500 \mathrm{mg} / \mathrm{kg}$ ) (Fig. 7a) or sodium pentobarbital (50 mg/kg) (Fig. 7c). The whole L4 DRG exposure surgery and in vivo DRG $\mathrm{Ca}^{2+}$ imaging were performed as previously described. ${ }^{65}$ The second chloral hydrate injection was done after the surgery was finished. Then mice were laid down in the stage and maintained at $36{ }^{\circ} \mathrm{C} \pm$ $0.5^{\circ} \mathrm{C}$ on the heating pad and rectal temperature was monitored during whole period. Live images were acquired at typically eleven frames with $600 \mathrm{~Hz}$ in frame-scan mode per $\sim 7 \mathrm{~s}$, at depths below the dura ranging from 0 to $70 \mathrm{~mm}$, using a $5 \times 0.5 \mathrm{NA}$ macro dry objective at typically $512 \times 512$ pixel resolution with solid diode lasers (Leica) tuned at $488 \mathrm{~nm}$ wavelength and emission at 500-549 $\mathrm{nm}$ for green fluorescence. For analysis, raw image stacks $(512 \times 512$ pixels in the $x-y$ plane and $20-30 \mathrm{~mm}$ voxel depth; typically 10 optical sections) were imported into ImageJ (NIH) for further analysis.

Stimulus delivery during in vivo L4 DRG imaging experiments The various temperature water stimuli were delivered using single channel bipolar temperature controller system (CL-100, Warner Instruments), which was performed on the hind paws of mice. At every trial, water at the adaptation temperature was the skin temperature of hind paw $\left(27^{\circ} \mathrm{C}\right)$. The L4 DRG imaging was performed for the first 3 frames imaged ( 21 s) at adaptation temperature to get baseline fluorescence and noise. The flow was switched to water at pre-heated various stimulation temperatures with the same flow rate. This switch led to rapid changes of temperature in hind paw for 4 frames imaged $(\sim 28 \mathrm{~s})$. Then the flow was switched back to adaptation temperature for 4 frames imaged ( 28 s). The next trial was performed after at least 5 min.

In vivo $\mathrm{L} 4 \mathrm{DRG} \mathrm{Ca}^{2+}$ imaging data analysis

For imaging data analysis, raw image stacks were collected, deconvoluted (if needed), and imported into ImageJ (NIH) for further analysis as previously described. ${ }^{65}$ All putative responding neurons were verified by visual examination using the raw imaging data. First, analyzers visually scored cells to identify stimulus-evoked $\mathrm{Ca}^{2+}$ transients in DRG neurons by directly observing the aligned image data displayed as a relative fluorescence movie, as well as the putative responding neurons' fluorescence time series. Analyzers defined $\mathrm{Ca}^{2+}$ transients as stimulus evoked if their onsets occurred between the start of stimulation and the $28 \mathrm{~s}$ (4 DRG images) after the end of stimulation (it takes $\sim 7 \mathrm{~s}$ to obtain a full, single DRG image). $\mathrm{Ca}^{2+}$ signal amplitudes were expressed as $\left(\mathrm{F}_{\mathrm{t}}-\mathrm{F}_{0}\right) / \mathrm{F}_{0}$ as a function of time, ratio of fluorescence difference $\left(\mathrm{F}_{\mathrm{t}}-\mathrm{F}_{0}\right)$ to basal value $\left(\mathrm{F}_{0}\right)$. The average fluorescence intensity in the baseline period was taken as $F_{0}$ and measured as the average pixel intensity during the first 3 frames of each imaging trial. The maximum fluorescence intensity $F_{t}$ was measured by calculating the average (peak-background) pixel values in a given region of interest (ROI) for each image frame recorded during a time interval before and during the stimulation period. The $\mathrm{F}_{\mathrm{t}}$ was used to calculate $\Delta \mathrm{F} / \mathrm{F}$ using the formula $\Delta \mathrm{F} / \mathrm{F}=\left(\mathrm{Ft}-\mathrm{F}_{0}\right) / \mathrm{F}_{0}$. The neurons with $\Delta \mathrm{F} / \mathrm{F}>0.2$ was considered as responding neurons.

Statistical methods

Data in all figures are shown as mean \pm SEM. The number of tested animals or separate experiments was labeled in the figure or figure legend, respectively. Statistical significance was evaluated using the method indicated in the figure legends.

\section{ACKNOWLEDGEMENTS}

This study was initiated in Dr. Ardem Patapoutian's laboratory, and we thank him for his tremendous support. We thank Dr. Anjana Rao for generously sharing the $\mathrm{STIM} 1^{\mathrm{fl} / \mathrm{fl}}$ mice; Drs. Donald Gill and Youjun Wang (Beijing Normal University) for sharing the Orai-KO-HEK cell lines; Drs. Sanjue Hu, Junlin Xin and Xiaohui Liu for technical help; R. Eddins, R. Miramontes and M. Frazer for managing the constitutive STIM1 KO mouse line, and J. Avis, C. Wilmot, C. Cienfuegos and E. Hesek for technical help in the generation and genotyping of the mice; the animal core facility at Tsinghua University for maintaining the other lines of mice used in the study. We thank Drs. Ardem Patapoutian (The Scripps Research Institute), Mohamed Trebak (Pennsylvania State University College of Medicine), Hongzhen Hu (Washington University), Yubin Zhou (Texas A\&M University Health Science Center) and Youjun Wang for critically reading the manuscript. This work was supported by the National Natural Science Foundation of China (31371118, 31825014, 31630090 and 31422027), the National Key R\&D Program of China (2016YFA0500402 and 2015CB910102), and the Young Thousand Talent Program to B.X.

\section{AUTHOR CONTRIBUTIONS}

$X$. L. and Y. J. generated the STIM1- $\Delta K$ knock-in mice, designed and carried out the cellular and biochemical experiments and analyzed the data. H. W. and M. P. performed behavioral experiments and analyzed the data. Q. Z. performed in vivo DRG $\mathrm{Ca}^{2+}$ imaging studies and analyzed the data. M. Z. helped the cellular experiments. S. Z. generated the Orai-KO-HEK cell lines. C. S. supervised the generation and genotyping of the constitutive STIM1-knockout mice. D. X. supervised the in vivo DRG $\mathrm{Ca}^{2+}$ imaging studies. B. X. conceived and supervised the project, conceptualized the model, made figures and wrote the paper with help from all the authors. All authors read and discussed the paper.

\section{ADDITIONAL INFORMATION}

Supplementary information accompanies this paper at https://doi.org/10.1038/ s41422-018-0129-0.

Competing interests: The authors declare no competing interests.

Publisher's note: Springer Nature remains neutral with regard to jurisdictional claims in published maps and institutional affiliations.

\section{REFERENCES}

1. Dhaka, A., Viswanath, V. \& Patapoutian, A. Trp ion channels and temperature sensation. Annu. Rev. Neurosci. 29, 135-161 (2006).

2. Vriens, J., Nilius, B. \& Voets, T. Peripheral thermosensation in mammals. Nat. Rev. Neurosci. 15, 573-589 (2014).

3. Palkar, R., Lippoldt, E. K. \& McKemy, D. D. The molecular and cellular basis of thermosensation in mammals. Curr. Opin. Neurobiol. 34, 14-19 (2015).

4. Caterina, M. J. et al. The capsaicin receptor: a heat-activated ion channel in the pain pathway. Nature 389, 816-824 (1997).

5. Caterina, M. J., Rosen, T. A., Tominaga, M., Brake, A. J. \& Julius, D. A capsaicinreceptor homologue with a high threshold for noxious heat. Nature 398, 436-441 (1999).

6. Vriens, J. et al. TRPM3 is a nociceptor channel involved in the detection of noxious heat. Neuron 70, 482-494 (2011).

7. Tan, C. H. \& McNaughton, P. A. The TRPM2 ion channel is required for sensitivity to warmth. Nature 536, 460-463 (2016).

8. McKemy, D. D., Neuhausser, W. M. \& Julius, D. Identification of a cold receptor reveals a general role for TRP channels in thermosensation. Nature 416, 52-58 (2002).

9. Peier, A. M. et al. A TRP channel that senses cold stimuli and menthol. Cell 108, 705-715 (2002).

10. Story, G. M. et al. ANKTM1, a TRP-like channel expressed in nociceptive neurons, is activated by cold temperatures. Cell 112, 819-829 (2003).

11. Pogorzala, L. A., Mishra, S. K. \& Hoon, M. A. The cellular code for mammalian thermosensation. J. Neurosci. 33, 5533-5541 (2013).

12. Dhaka, A. et al. TRPM8 is required for cold sensation in mice. Neuron $\mathbf{5 4}, \mathbf{3 7 1 - 3 7 8}$ (2007).

13. Colburn, R. W. et al. Attenuated cold sensitivity in TRPM8 null mice. Neuron 54, 379-386 (2007) 
14. Bautista, D. M. et al. The menthol receptor TRPM8 is the principal detector of environmental cold. Nature 448, 204-208 (2007)

15. Caterina, M. J. et al. Impaired nociception and pain sensation in mice lacking the capsaicin receptor. Science 288, 306-313 (2000).

16. Park, U. et al. TRP vanilloid 2 knock-out mice are susceptible to perinatal lethality but display normal thermal and mechanical nociception. J. Neurosci. 31 11425-11436 (2011).

17. Vandewauw, I. et al. A TRP channel trio mediates acute noxious heat sensing. Nature 555, 662-666 (2018).

18. Lumpkin, E. A. \& Caterina, M. J. Mechanisms of sensory transduction in the skin. Nature 445, 858-865 (2007)

19. Peier, A. M. et al. A heat-sensitive TRP channel expressed in keratinocytes. Science 296, 2046-2049 (2002)

20. Guler, A. D. et al. Heat-evoked activation of the ion channel, TRPV4. J. Neurosci. 22, 6408-6414 (2002).

21. $\mathrm{Xu}, \mathrm{H}$. et al. TRPV3 is a calcium-permeable temperature-sensitive cation channel. Nature 418, 181-186 (2002).

22. Moqrich, A. et al. Impaired thermosensation in mice lacking TRPV3, a heat and camphor sensor in the skin. Science 307, 1468-1472 (2005).

23. Lee, H., lida, T., Mizuno, A., Suzuki, M. \& Caterina, M. J. Altered thermal selection behavior in mice lacking transient receptor potential vanilloid 4. J. Neurosci. 25, 1304-1310 (2005).

24. Huang, S. M., Li, X., Yu, Y., Wang, J. \& Caterina, M. J. TRPV3 and TRPV4 ion channels are not major contributors to mouse heat sensation. Mol. Pain. 7, 37 (2011).

25. Marics, I., Malapert, P., Reynders, A., Gaillard, S. \& Moqrich, A. Acute heat-evoked temperature sensation is impaired but not abolished in mice lacking TRPV1 and TRPV3 channels. PLoS One 9, e99828 (2014).

26. Miyamoto, T., Petrus, M. J., Dubin, A. E. \& Patapoutian, A. TRPV3 regulates nitric oxide synthase-independent nitric oxide synthesis in the skin. Nat. Commun. 2, 369 (2011).

27. Yarmolinsky, D. A. et al. Coding and plasticity in the mammalian thermosensory system. Neuron 92, 1079-1092 (2016).

28. Xiao, B., Coste, B., Mathur, J. \& Patapoutian, A. Temperature-dependent STIM1 activation induces $\mathrm{Ca}(2)+$ influx and modulates gene expression. Nat. Chem. Biol. 7, 351-358 (2011).

29. Hogan, P. G., Lewis, R. S. \& Rao, A. Molecular basis of calcium signaling in lymphocytes: STIM and ORAI. Annu. Rev. Immunol. 28, 491-533 (2010).

30. Soboloff, J., Rothberg, B. S., Madesh, M. \& Gill, D. L. STIM proteins: dynamic calcium signal transducers. Nat. Rev. Mol. Cell Biol. 13, 549-565 (2012).

31. Gwack, Y. et al. Hair loss and defective T- and B-cell function in mice lacking ORAl1. Mol. Cell. Biol. 28, 5209-5222 (2008).

32. Wilson, S. R. et al. The epithelial cell-derived atopic dermatitis cytokine TSLP activates neurons to induce itch. Cell 155, 285-295 (2013).

33. Vandenberghe, $M$. et al. ORAl1 calcium channel orchestrates skin homeostasis. Proc. Natl. Acad. Sci. USA 110, E4839-E4848 (2013).

34. Numaga-Tomita, T. \& Putney, J. W. Role of STIM1- and Orai1-mediated Ca2+entry in $\mathrm{Ca}^{2+}$-induced epidermal keratinocyte differentiation. J. Cell. Sci. 126, 605-612 (2013).

35. Zhang, S. L. et al. STIM1 is a $\mathrm{Ca}^{2+}$ sensor that activates CRAC channels and migrates from the $\mathrm{Ca}^{2+}$ store to the plasma membrane. Nature 437, 902-905 (2005).

36. Roos, J. et al. STIM1, an essential and conserved component of store-operated $\mathrm{Ca}^{2+}$ channel function. J. Cell. Biol. 169, 435-445 (2005).

37. Zhang, S. L. et al. Genome-wide RNAi screen of $\mathrm{Ca}(2+)$ influx identifies genes that regulate $\mathrm{Ca}(2+)$ release-activated $\mathrm{Ca}(2+)$ channel activity. Proc. Natl. Acad. Sci. USA 103, 9357-9362 (2006)

38. Feske, S. et al. A mutation in Orai1 causes immune deficiency by abrogating CRAC channel function. Nature 441, 179-185 (2006).

39. Vig, M. et al. CRACM1 is a plasma membrane protein essential for store-operated $\mathrm{Ca}^{2+}$ entry. Science 312, 1220-1223 (2006).

40. Woo, S. H. et al. Piezo2 is required for Merkel-cell mechanotransduction. Nature 509, 622-626 (2014).
41. Stiber, J. et al. STIM1 signalling controls store-operated calcium entry required for development and contractile function in skeletal muscle. Nat. Cell Biol. 10 688-697 (2008).

42. Chung, M. K., Lee, H., Mizuno, A., Suzuki, M. \& Caterina, M. J. TRPV3 and TRPV4 mediate warmth-evoked currents in primary mouse keratinocytes. J. Biol. Chem. 279, 21569-21575 (2004).

43. Oh-Hora, M. et al. Dual functions for the endoplasmic reticulum calcium sensors STIM1 and STIM2 in T cell activation and tolerance. Nat. Immunol. 9, 432-443 (2008).

44. Dassule, H. R., Lewis, P., Bei, M., Maas, R. \& McMahon, A. P. Sonic hedgehog regulates growth and morphogenesis of the tooth. Development 127, 4775-4785 (2000).

45. Zhou, Y. et al. The STIM1-binding site nexus remotely controls Orai1 channel gating. Nat. Commun. 7, 13725 (2016)

46. Zheng, S. et al. Calcium store refilling and STIM activation in STIM- and Oraideficient cell lines. Pflugers Arch. https://doi.org/10.1007/s00424-018-2165-5 (2018).

47. Peinelt, C., Lis, A., Beck, A., Fleig, A. \& Penner, R. 2-Aminoethoxydiphenyl borate directly facilitates and indirectly inhibits STIM1-dependent gating of CRAC channels. J. Physiol. 586, 3061-3073 (2008).

48. Zhang, X. et al. Mechanisms of STIM1 activation of store-independent leukotriene C4-regulated $\mathrm{Ca}^{2+}$ channels. Mol. Cell. Biol. 33, 3715-3723 (2013).

49. Gonzalez-Cobos, J. C. et al. Store-independent Orai $1 / 3$ channels activated by intracrine leukotriene C4: role in neointimal hyperplasia. Circ. Res. 112, 1013-1025 (2013)

50. Baumbauer, K. M. et al. Keratinocytes can modulate and directly initiate nociceptive responses. ELife 4, https://doi.org/10.7554/eLife.09674 (2015).

51. Pang, Z. et al. Selective keratinocyte stimulation is sufficient to evoke nociception in mice. Pain 156, 656-665 (2015).

52. Schepers, R. J. \& Ringkamp, M. Thermoreceptors and thermosensitive afferents. Neurosci. Biobehav. Rev. 34, 177-184 (2010).

53. Zappia, K. J. et al. Mechanosensory and ATP release deficits following Keratin14Cre-mediated TRPA1 deletion despite absence of TRPA1 in murine keratinocytes. PLoS One 11, e0151602 (2016).

54. Bautista, D. M., Pellegrino, M. \& Tsunozaki, M. TRPA1: a gatekeeper for inflammation. Annu. Rev. Physiol. 75, 181-200 (2013).

55. Macpherson, L. J. et al. An ion channel essential for sensing chemical damage. J. Neurosci. 27, 11412-11415 (2007)

56. Huang, S. M. et al. Overexpressed transient receptor potential vanilloid 3 ion channels in skin keratinocytes modulate pain sensitivity via prostaglandin E2. J. Neurosci. 28, 13727-13737 (2008).

57. Mandadi, S. et al. TRPV 3 in keratinocytes transmits temperature information to sensory neurons via ATP. Pflug. Arch. 458, 1093-1102 (2009).

58. Moore, $C$. et al. UVB radiation generates sunburn pain and affects skin by activating epidermal TRPV4 ion channels and triggering endothelin-1 signaling. Proc. Natl. Acad. Sci. USA 110, E3225-E3234 (2013).

59. Cho, $\mathrm{H}$. et al. The calcium-activated chloride channel anoctamin 1 acts as a heat sensor in nociceptive neurons. Nat. Neurosci. 15, 1015-1021 (2012).

60. Souslova, V. et al. Warm-coding deficits and aberrant inflammatory pain in mice lacking P2X3 receptors. Nature 407, 1015-1017 (2000).

61. Shimizu, I. et al. Enhanced thermal avoidance in mice lacking the ATP receptor P2X3. Pain 116, 96-108 (2005).

62. Murota, H. \& Katayama, I. Evolving understanding on the aetiology of thermally provoked itch. Eur. J. Pain. 20, 47-50 (2016).

63. Boulant, J. A. Neuronal basis of Hammel's model for set-point thermoregulation. J. Appl. Physiol. 100, 1347-1354 (2006).

64. Grandl, J. et al. Pore region of TRPV3 ion channel is specifically required for heat activation. Nat. Neurosci. 11, 1007-1013 (2008).

65. Kim, Y. S. et al. Coupled activation of primary sensory neurons contributes to chronic pain. Neuron 91, 1085-1096 (2016). 